\title{
Framework for Integrated Dynamic Thermal Simulation of Future Civil Transport Aircraft
}

\author{
Albert S.J. van Heerden*, David M. Judt ${ }^{\dagger}$, Craig P. Lawson ${ }^{\ddagger}$, Soheil Jafari ${ }^{\S}$, Theoklis Nikolaidis ${ }^{\text {If }}$ \\ Cranfield University, College Rd, Bedford, MK43 OAL, United Kingdom \\ David Bosak"l \\ Meggitt PLC, Holbrook Lane, Coventry, CV6 4AA, United Kingdom
}

\begin{abstract}
The development of increasingly more electric systems and ultra high bypass ratio turbofan engines for civil transport aircraft is projected to bring forth critical challenges regarding thermal management. To address these, it is required that the thermal behavior of the complete propulsion-airframe unit is studied in an integrated manner. To this purpose, a simulation framework for performing integrated thermal and performance analyses of the engines, airframe, and airframe systems, is presented. The framework was specifically devised to test novel integrated thermal management solutions for future civil aircraft. In this paper, the discussion focuses mainly on the thermal modeling of the wing and fuel. A highly flexible approach for creating wing thermal models by means of assembling generic thermal compartments is introduced. To demonstrate some of the capabilities, a case study is provided that involves thermal analysis of a single-aisle airplane with ultra high bypass ratio engines. Results are provided for fuel temperatures across flights in standard, hot, and cold days and for different airframe materials. Engine heat sink temperatures and input power to the engine gearboxes, both important parameters needed to design thermal management systems, are also presented.
\end{abstract}

\section{Nomenclature}

$\begin{array}{ll}A & =\text { Area }\left[\mathrm{m}^{2}\right] \\ \text { AOHE } & =\text { Air-Oil Heat Exchanger } \\ \text { CFRP } & =\text { Carbon-Fiber Reinforced Polymer } \\ c_{p} & =\text { Specific heat capacity }\left[\frac{\mathrm{J}}{\mathrm{kgK}}\right] \\ d & =\text { Wall thickness }[\mathrm{m}] \\ \text { ECS } & =\text { Environmental Control System } \\ \text { EHA } & =\text { Electro-Hydrostatic Actuator } \\ \text { EMA } & =\text { Electro-Mechanical Actuator } \\ \text { FAA } & =\text { US) Federal Aviation Administration } \\ \text { FARs } & =\text { (US) Federal Aviation Regulations } \\ \text { FCS } & =\text { Flight Control System } \\ \text { FOHE } & =\text { Fuel-Oil Heat Exchanger } \\ \text { GTF } & =\text { Geared Turbofan } \\ h & =\text { Heat transfer coefficient }\left[\frac{\mathrm{W}}{\mathrm{m}^{2} \mathrm{~K}}\right]\end{array}$

\footnotetext{
Research Fellow, Centre for Aeronautics. AIAA Member.

$\dagger$ Lecturer, Centre for Aeronautics.

$\doteqdot$ Senior Lecturer, Centre for Aeronautics.

$\S$ Research Fellow, Centre for Propulsion Engineering.

"Reader, Centre for Propulsion Engineering.

$\|$ Principal Engineer
}

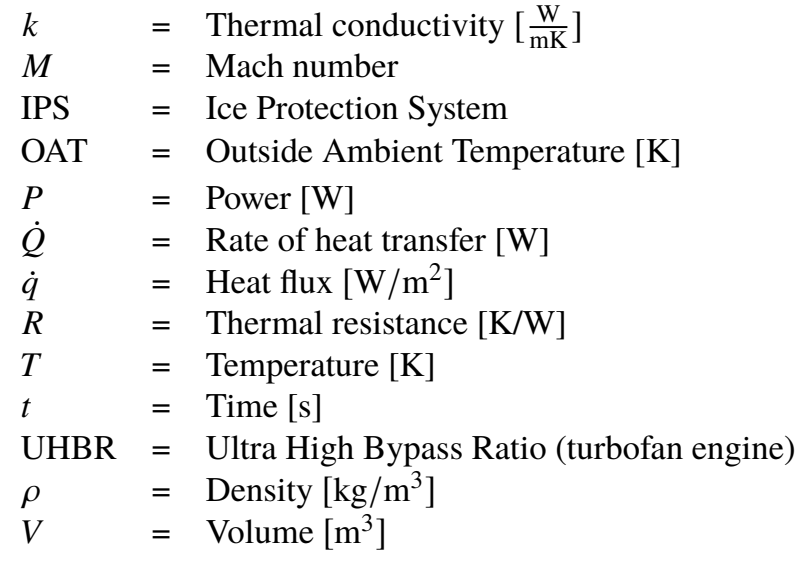




\section{Introduction}

$\mathrm{T}$

HE design of future civil transport aircraft must address the ambitious goals set by the Advisory Council for Aviation Research and innovation in Europe (ACARE) in Flightpath 2050. These include a 75\% reduction in $\mathrm{CO}_{2}$ emissions and $90 \%$ reduction in Nitrogen Oxides (NOx) emissions [1]. Towards meeting this challenge, electrification (i.e. the 'More-Electric Aircraft') [2], as well as Geared Turbofan (GTF) with Ultra High Bypass Ratio (UHBR) engines [3] have been suggested in the literature as some of the most promising intermediate solutions.

However, it is projected that these concepts will bring forth critical challenges regarding thermal management. For GTF UHBR engines, there are several reasons for this, including diminishing heat sink capacity in the engine, lower core compartment ventilation, and large quantities of waste heat expected from the large power gearbox [4-6]. For more-electric aircraft, the thermal management challenges arise due to excess waste heat from electrical components, such as power electronics [5], electrically powered actuators [7], and the generators required [8]. Adding to these factors are the increased use of composite materials, which reduces the ability of the airframe to reject waste heat to the atmosphere.

To enable the successful introduction of these technologies, the magnitude of this thermal management problem has to be understood and innovative solutions will need to be devised. Producing such solutions would necessarily have to involve aircraft-level investigation, as expanded utilization of existing, or the introduction of new, heat sinks in the airframe would likely be needed. Considering the propulsion, airframe, and airframe systems together in such an aircraft-level investigation might also lead to overall more efficient solutions.

Of particular importance would be to study the effects of additional heat loads on one of the principal heat sinks on the aircraft - the fuel. Fuel tanks are large and efficient heat sinks, but closely coupled to safety considerations. They therefore require a detailed thermal representation to complete an aircraft operational linked fleet level flammability assessment (i.e. for both parts of the FAA FAR Part 25.981 [fuel tank explosion prevention] regulations [9]).

To address these considerations, an integrated dynamic simulation framework for investigating the overall thermal behavior of civil transport aircraft was developed. 'Integrated' refers to the notion that the whole aircraft and its major subsystems are to be simulated, along with the engines. This requires coupled aircraft and engine performance, atmosphere, aircraft subsystems, and thermal models. 'Dynamic' refers to the need to simulate the time-varying nature of the thermal behavior. The intended purpose of this framework is to enable investigating novel integrated airframe-systems-propulsion thermal management approaches. The framework had to support dynamic simulation of the following:

- Aircraft performance across different flight profiles and atmospheric cases.

- Propulsion performance and engine component thermal behavior.

- Airframe, especially wing, thermal behavior.

- Thermal behavior of the fuel.

- The operation of major airframe systems and their effects on the overall thermal behavior of the aircraft.

The framework is currently being produced by Cranfield University in partnership with Meggitt PLC. The work forms part of a larger multidisciplinary effort, called the 'UHBR Thermals' Program. This Innovate UK and Meggitt PLC funded research program aims to investigate engine and airframe heat exchange concepts for future UHBR geared turbofan engines and to quantify their benefit at the system and aircraft level [10].

This paper is devoted to the development of this framework and its implementation into a software tool. The focus is primarily on the wing and fuel thermal modeling, but descriptions are provided for all the models in the framework.

This introduction is followed in Section [II] by a discussion on the factors that need to be considered in modeling aircraft thermal behavior. In Section[IV] the framework is presented and its different constituent elements are introduced. A detailed discussion of the wing and fuel thermal modeling is also presented in this section. Section $\nabla$ briefly covers how the wing thermal model was validated, while Section VI contains some sample results for a case study aircraft. Finally, the discussion is concluded in Section VII

\section{Thermal behavior in civil transport aircraft}

In this section, the different factors, heat sources, and heat sinks that must be considered when attempting to simulate aircraft thermal behavior are briefly introduced. In line with the scope of the paper, particular emphasis is placed on wing and fuel thermal behavior. 


\section{A. Outside environment}

Commercial aircraft must be able to operate in outside air temperatures ranging from less than $-40^{\circ} \mathrm{C}$ to more than $50^{\circ} \mathrm{C}$ [11], as well as deal with solar radiation. The actual airframe skin temperature will be affected by 'kinetic heating', which occurs because of friction between the skin and the air molecules. This temperature is known as the recovery temperature. The leading edges on the aircraft will actually experience more heating and the associated higher temperature is referred to as 'ram air temperature'. The wide range of operating temperatures has important implications for structural design, environmental control, airframe systems, fuel system safety, and many others.

\section{B. Engine and engine component heat sources}

In gas turbine engines, heat is generated primarily by the combustion of fuel and the compression of air [12]. However, there are also parasitic sources, such as friction, oil churning, windage, or an oversized core [12]. The sinks are mainly fuel and air (in the bypass duct) [12] and heat is transported to them by the engine oil by means of heat exchangers. These add mass and can contribute to drag. Typical heat sinks and parasitic heat sources are summarized in Table 1.

As alluded to in the introduction, in UHBR engines, it is expected that severe additional challenges related to thermal management will arise. There are several reasons

Table 1 Typical main parasitic heat sources and heat sinks in turbofan engines.

\begin{tabular}{ll}
\hline Heat sources & $\overline{\text { Heat sinks }}$ \\
\hline Power gearbox (in GTF & Fuel \\
UHBR engines) & \\
Accessory gearbox & Bypass duct air \\
Bearings & Engine components \\
Electrical generators & \\
Constant speed drive & \\
Pumps & \\
\hline
\end{tabular}
for this. First, the higher bypass ratios lead to larger nacelle weight and cowl drag. This can be alleviated by moving some components that are installed in the nacelle to the core of the engine - thus making the nacelle more slim and aerodynamically efficient. However, with such an arrangement, there is less space overall for heat dissipating equipment. Secondly, the larger fan diameters of UHBR engines lead to higher blade tip speeds, with the tips potentially reaching the speed of sound. This will deteriorate the pressure rise capacity of the blade - negatively impacting fuel consumption. The fan blade tip speed can be reduced by lowering low-pressure (LP) shaft speed. However, if the LP shaft speed is lowered, the turbine blades need to have higher span to expand the air to the desired pressure. This would lead to a higher diameter of the turbine casing and higher weight of the turbine section. Therefore, it is desired to have the fan run slower, but the turbine to run faster. This is where a requirement for a power gearbox arises.

The geared technology allows the low pressure (LP) compressor to run at a higher rotational speed than the fan, allowing for fewer stages to be used in both the LP turbine and the LP compressor. However, a substantial amount of energy will be lost as heat in the gear mechanism. This thermal load must be managed by thermal management systems (TMS), which transfer excess heat from the engine heat sources to engine fluids (the heat sinks). There are implementation considerations that limit the capacity of the heat sinks to absorb the thermal loads from heat sources:

- The TMS size and weight is limited by the engine design and geometry.

- The allowable temperature range for fuel and oil must be maintained, as the engine oil may undergo coking and fuel may undergo lacquering, gumming, or varnishing above certain temperature limits [13].

Another engine heat source that will become increasingly significant are the engine-driven electrical generators. This is because of the growing electrification of aircraft, which would lead to considerably higher electrical demands than current aircraft and subsequent higher heat loads.

\section{Airframe heat sources}

There are several significant heat sources on transport aircraft. The largest of these are the engines (as discussed in the previous subsection), but the payload (passengers), environmental control system, and other airframe systems also contribute large heat loads that have to be managed. These are briefly discussed in this section.

\section{Crew and passengers}

Human occupants produce a considerable amount of heat on board the aircraft, contributing both 'sensible' and 'latent' heat. Sensible heat refers to heat transferred between the human occupants and their colder surroundings by means of convection, conduction, and radiation [11]. Latent heat refers to the heat released by condensation of water 
vapor from the breath of the occupants [11]. The role of producing a habitable and comfortable onboard environment for the occupants, which, among others, involves managing cabin temperature, is assigned to the environmental control system. This system is described next.

\section{Environmental control system}

In the context of thermal management, the environmental control system (ECS) can be considered to be a thermal transport system (removing or providing heat from/to the cabin), but also as a heat source (through its constituent components). The primary role of the ECS is to provide an acceptable environment for the human occupants and aircraft systems. It must pressurize the cabin, distribute conditioned air around the cabin, and remove from the cabin excess heat produced by the occupants, electrical equipment, galleys, and other systems [11].

Traditionally, to perform pressurization, compressed air is bled from the compressor stages of the engines. The bled air is transported through ducts to air conditioning (A/C) packs (also referred to as ECS packs). The A/C packs can get considerably hot and, because of their proximity to center fuel tanks (a commonly used configuration), can produce an additional heat load in the fuel that must be accounted for.

In a more-electric systems architecture, the role of pressurization could be fulfilled by compressors driven by electrical motors. In such an architecture, bleed air ducts are eliminated, reducing the thermal load on the surrounding structure. However, the increase in electrical power required leads to larger generators, which produce additional waste heat in the engine. Furthermore, the motors and power electronics that control them can also produce substantial amounts of waste heat. These effects need to be accounted for when devising thermal management systems.

\section{Other airframe systems}

There are several other important heat sources on board the aircraft. Some of the more significant of these are associated with the ice-protection system, electrical equipment, the hydraulic system and its components, and flight control actuators.

The ice-protection system (IPS) removes and prevents a build-up of ice at specific locations on the airplane. For the engine nacelles and wing leading edges, bleed air is traditionally used for this purpose. As with the ECS, the ducting can cause additional thermal loads on the fuel tanks.

Electrical equipment can produce a substantial amount of heat and prolonged operations at high temperature negatively affect their reliability. Waste heat produced by the electrical distribution system (which include power distribution units and 'power feeders' [thick cables]) also needs to be considered. The task of cooling the electrical equipment bays traditionally falls to the air distribution system of the ECS [11]. In more-electric aircraft, apart from the extra heat load from potential larger generators, there could be considerably more heat-producing electrical equipment scattered across the aircraft. In some cases, dedicated local liquid cooling systems are required to remove the waste heat from these components.

Another source of heat is the hydraulic power system (HPS). As hydraulic fluid is pumped to maintain pressure, it heats up and the heated fluid travels across the hydraulic network. Regarding hydraulic actuators for flight control surfaces, doors, and so forth, traditional actuators do not produce a significant amount of waste heat [14]. This is different with newer, more-electric actuators, such as Electro-Hydrostatic and Electro-Mechanical Actuators (EHAs and EMAs). These can produce significant localized waste heat and, in some case, such as with the aileron EHAs on the Airbus A380, a dedicated cooling system is required as part of their implementation [14].

\section{Heat sinks}

The primary heat sinks on commercial aircraft are the fuel and ambient air. Other intermediate heat sinks may exist, but usually heat is eventually rejected to either the fuel or ambient air.

\section{Ambient air}

As a sink, ambient air could be exploited through the use of heat exchangers (air-to-air or air-to-liquid). These could be embedded in the skin (i.e. skin heat exchangers), or ambient air could be sourced through ram air ducts. Examples of heat exchangers using ambient air to cool aircraft and engine systems include air-oil heat exchangers (AOHEs) in the engine bypass duct, air-air heat exchangers in the air-conditioning packs, and skin heat exchangers for cooling electrical equipment bays. Using ram air as a coolant is associated with additional drag, which has to be considered when designing and optimizing thermal management systems. 
Table 2 Summary of fuel tank thermal modeling approaches.

\begin{tabular}{lll}
\hline \hline Approach & Governing relationship & References \\
\hline Bulk 1-D steady state models & $\sum Q_{\text {loss }}+\frac{\Delta T}{R}=0$ & [19]-21]. \\
Bulk 1-D transient models & $\rho C V \frac{d T}{d t}=\sum Q_{\text {loss }}$ & [21]-26] \\
Finite volume 1-D transient models & $\left(\rho C V \frac{d T}{d t}\right)_{i}=\left(\sum Q_{\text {loss }}\right)_{i+1, i-1}$ & [27] \\
3-D heat diffusion CFD model & $\frac{\delta}{\delta x, y, z}\left(k \frac{\delta T}{\delta(x, y, z)}\right)+\dot{q}=\rho c \frac{\delta T}{\delta t}$ & [28] \\
\hline \hline
\end{tabular}

\section{Fuel}

Fuel is an important heat sink in civil aircraft and is used to cool several systems, such as engine components, hydraulics, and electronics [11]. It is a reasonably effective sink, as its temperature can drop significantly during a flight. This is because the fuel tanks are normally integral to the wing structure, with only the airframe skin separating the fuel from the cold atmosphere. Rejecting heat to the fuel has the additional benefit of keeping it from freezing, which reduces the risk of fuel system component icing failures. Disadvantages of using fuel as a heat sink, apart from the inherent safety concerns, include that its quantity reduces during a flight and its temperature is higher early in the flight, both diminishing its capacity to act as a sink. Both the mass of fuel available and its bulk temperature is therefore important.

Waste heat can be rejected to the fuel on its way to the engines (such as with fuel-oil engine heat exchangers (FOHEs) that cool engine oil), or directly into the fuel tanks, by means of heat exchangers submerged in the fuel. The former method provides some benefit regarding fuel consumption, because of the higher calorific value associated with the heated fuel [15]. However, the fuel can only be heated up to a certain maximum allowable temperature. In some aircraft, such as the Airbus A320, heated fuel is sometimes recirculated back to the fuel tank [16]. This provides for a higher mass flow rate, which provides increased cooling capacity without increasing the temperature of the fuel feed beyond acceptable limits. This leads to higher fuel temperatures in the tanks, which could be beneficial in cases where the fuel is dangerously cold, but problematic when it is in/close to a flammable state.

Fuel flammability is a major concern in the design and operation of fuel tanks. Flammability is associated with the risk of an explosion in the presence of an ignition source. The upper and lower fuel flammability limits can be calculated as prescribed in the European Aviation Safety Agency (EASA) CS-25 requirements [17]. These calculations are based on the flash point of the fuel, which is about $38^{\circ} \mathrm{C}$. At sea level, the lower flammability limit is the flash point minus $5.5^{\circ} \mathrm{C}$. It decreases by $0.55^{\circ} \mathrm{C}$ for every $808 \mathrm{ft}$ of altitude gained. The upper flammability limit is the flash point plus $19.5^{\circ} \mathrm{C}$ at sea level and decreases by $0.55^{\circ} \mathrm{C}$ for every $512 \mathrm{ft}$ of altitude gained. When the fuel temperature is between these limits, the fuel is flammable if the oxygen concentration in the ullage is higher than $12 \%$ between sea-level and 10 $000 \mathrm{ft}$, or above the linear increase of this value up to $14.5 \%$ at $40000 \mathrm{ft}$. Although fuel is allowed to be within the flammable range, the total time the fuel tanks of a fleet of the aircraft under consideration is flammable must be limited.

Modeling the thermal behavior of the fuel tank, along with the surrounding atmosphere and system heat sources across whole missions is therefore of prime importance in any aircraft level thermal behavior investigation. The discussion that follows is duly devoted to the literature on fuel tank thermal modeling.

A summary of approaches is provided in Table 2 In equilibrium and transient 1-D models, a fuel tank is divided into individual tank units, with each containing a number of temperature nodes at the boundaries [18-20]. The equilibrium assumption states that upper and lower wall nodes have the same temperature as the external atmosphere. With these boundary conditions, the ullage and fuel nodes of each tank unit can be calculated iteratively using one-dimensional heat transfer equations for conduction or convection. This approach has also been adapted to a transient case by eliminating the assumption of equilibrium temperature at the walls [21]. In this case, additional unknown nodes for the walls are introduced and the atmospheric nodes become the boundary conditions.

Tank walls may also be treated with additional nodes and subsequently solved for by means of a finite volume approach. This allows the external skin effects for both convective and radiative effects to be captured in combination with skins having different material properties for the heat conduction calculations [22, 23].

In other work, a more detailed tank discretization was proposed, resulting in a discrete finite element energy approach [27]. The fuel tank is considered as a trapezoidal volume to simplify the ullage and fuel surface area estimation under different fill states. The main difference between equilibrium and transient models is the discretization of the fuel volume into further volume elements in the span direction. It is therefore possible to obtain a temperature distribution 
per element, rather than per tank volume. The tank walls are also treated in a finite element fashion, by discretizing them along the wingspan and wall thickness direction. The wing span direction discretization matches the fuel finite elements. Elements are then solved for conduction through the layers with the boundary conditions of the ambient at the last element. For each element, the 1-D transient heat equations are then solved using information from adjacent fuel and structure volume elements.

Detailed fluid dynamics simulations of a wing fuel tank, including a leading-edge bleed air duct have been conducted using a commercial CFD package [28]. The main benefit of taking this approach is the fact that detailed 3D heat maps of the fluid and the structure may be obtained. In addition, more complex phenomena, such as condensation and vaporization may be included. Generating results is however costly in terms of computational time and hence not suitable to be integrated in preliminary and whole-aircraft simulation environments. Other authors have adopted a hybrid approach by using detailed CFD to establish heat transfer coefficients at specific flow conditions, and then using those values during 1-D transient simulation runs of fuel tanks and fuel system components [24].

For the purpose of the work described in this paper, what was required was a computationally inexpensive wing/fuel tank thermal modeling method with which comparative studies could be performed. It was also required that the thermal effects of different surrounding system components on the fuel temperature be captured (a further extension of previous work by the authors - see [35]). In light of these requirements, the most suitable approach was deemed to adopt a 1-D modeling approach, similar to those described in the aforementioned literature, but to extend it to easily include compartments and equipment surrounding the fuel tanks. Another aspect that was needed for the current work was to develop a methodology with which thermal behavior models could swiftly be generated for substantially different wing and fuel tank layouts, without affecting the simulation structure itself. Addressing these aspects would render such a wing thermal modeling significantly comprehensive and flexible, in that many different aircraft configurations and systems could swiftly and easily be incorporated in the simulation framework.

\section{E. Previous integrated dynamic modeling and simulation approaches}

The need for integrated dynamic simulation of the thermal behavior of aircraft, which takes into account all the factors mentioned in the previous sections, has been recognized for some time in the academic and industrial community. Several approaches exist, mainly focusing on military applications. For example, McCarthy et al. [22] proposed a tool for analyzing thermal management systems for more-electric aircraft and employs this tool to demonstrate thermal management for a supersonic military aircraft with one fuel tank. Dooley, Lui, and Newman [29] presented results for novel integrated propulsion, power, and thermal management concepts on fighter aircraft. Wolff [30] introduced detailed models for an 'engine/vehicle' thermal management system, and demonstrated these on military aircraft during a specific maneuver, as well as on a case study where the effects of different power thermal management system architectures (which cools avionics and the cockpit) on fuel burn was determined. Another example is by Roberts and Decker [31], who presented an integrated control architecture study for a thermal management in a long-range strike fighter.

These approaches should, with some additional effort, be adaptable to any type of aircraft. However, there is a specific need for a dedicated framework that contains models for ultra high bypass turbofan engines, multiple connected fuel tanks, the comparatively large ECS, the effects on fuel temperature of system components surrounding the fuel tanks, and the overall impact of different architectures on fuel consumption and safety, across whole flights in different atmospheric conditions. As alluded to, such a framework is required to estimate the magnitude of thermal problems on future airliners with UHBR engines, as well as to test novel solutions to manage these problems. The framework was also required to be easily extendable to electrified propulsion aircraft, which further underpinned the need for flexible thermal models and the catering for the inclusion of subsystems, as described earlier. It was therefore decided to develop a bespoke framework with these capabilities for civil transport aircraft from the outset.

\section{Proposed simulation framework}

This section is devoted to describing the main elements of the proposed simulation framework. It was deemed that the most appropriate development platform would be MATLAB ${ }^{\circledR}$ Simulink ${ }^{\circledR}$, as this environment is highly suited to dynamic simulation of engineering systems. As will be discussed for the different simulation blocks, the framework was intended to be generic, such that different alternative systems architectures, thermal management approaches, and flight profiles (here termed 'missions') could easily be implemented. 


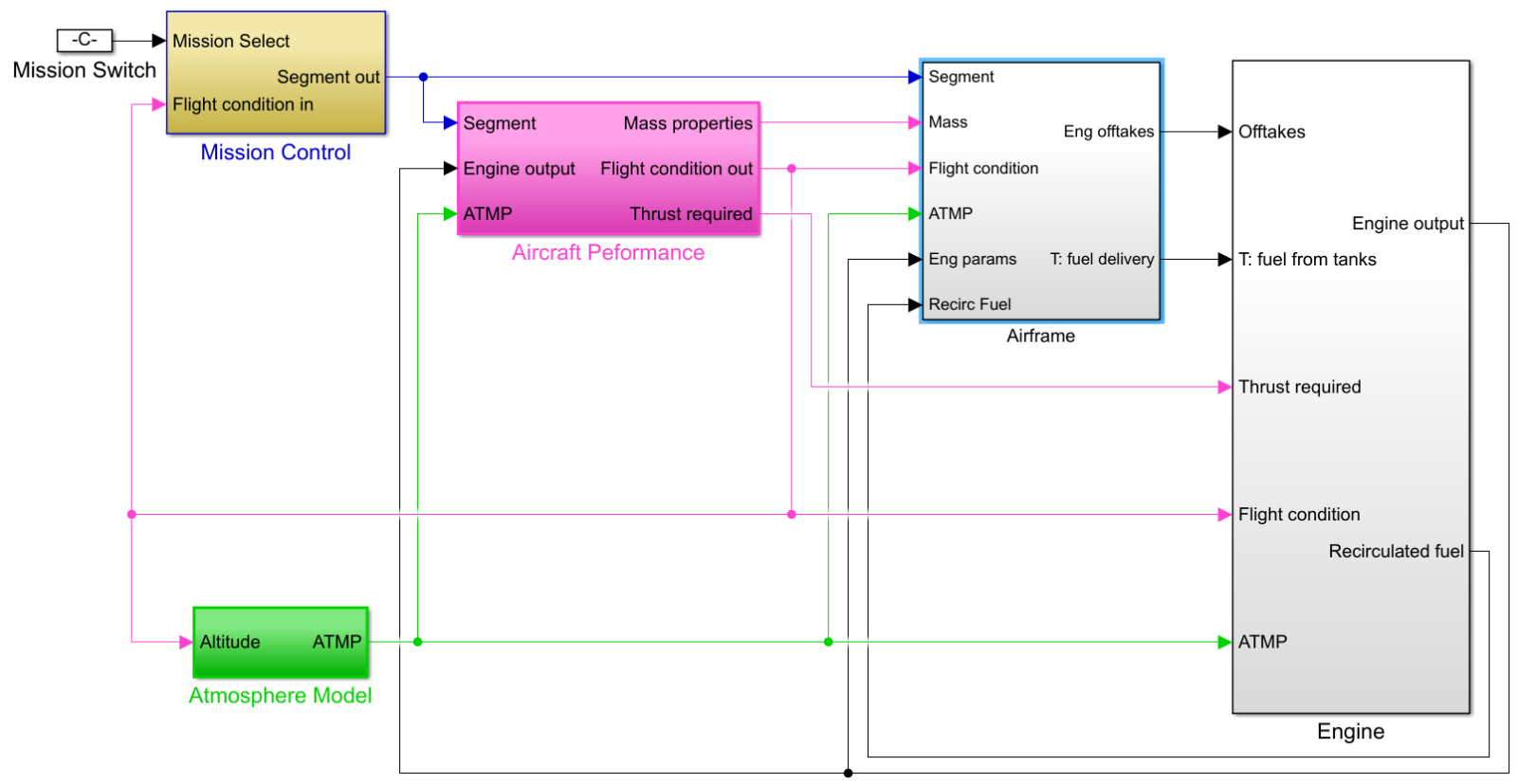

Fig. 1 Top-level Simulink block diagram of the simulation tool.

\section{A. Overview}

The top-level Simulink block diagram of the simulation tool is provided in Fig. 1. As can be seen, there are five top-level blocks - the 'Mission Control', 'Atmosphere Model', 'Aircraft Performance', 'Airframe', and 'Engine' blocks. The user can select a mission profile by inserting a mission number in the 'Mission Switch' constant block. The mission block determines when to switch between mission profile segments (e.g. climb, cruise, etc.) and outputs mission segment-specific parameters. A mission could also be defined in this block as a simple lookup table of altitudes and Mach numbers. Atmospheric conditions (temperature, pressure, density, etc.) are calculated in the Atmosphere Model block. The mission segment, atmospheric, and engine output information is then used in the Aircraft Performance block to update flight conditions (climb/descent rates, speed and altitude) and to calculate the thrust required from the engines. The Airframe block contains models of the airframe and main aircraft systems (but not engine systems). This block calculates secondary engine power offtakes required by the airframe systems, as well as the thermal behavior of the airframe (specifically the wing) and airframe systems. The engine block houses the engine performance and engine thermal management models.

To populate the MATLAB workspace with the required simulation parameters and model information, an initialization script is executed upon opening the Simulink model. The following information is loaded:

- The user-selected simulation time step. The simulation is set up to use a fixed time-step Euler (ode1) solver. Note that the blocks can be run at different simulation time steps, which allows for more efficient simulation.

- Aircraft geometry and mass, along with payload and fuel information.

- The atmospheric case (either 'standard', 'hot', or 'cold' day).

- The mission segment parameters (such as start/end altitude, Mach number, and so forth).

- Airframe systems information, such as cabin geometry (for the environmental control system), along with hydraulic, pneumatic, and electrical system parameters.

- Wing and fuel tank geometry data (used for wing thermal behavior simulation).

- Fuel and ullage initial temperatures.

- Aircraft aerodynamics data and performance tables, such as maximum climb rate, maximum climb angle, minimum drag speed, and so forth.

The different simulation blocks are covered in more detail in the subsections that follow. 


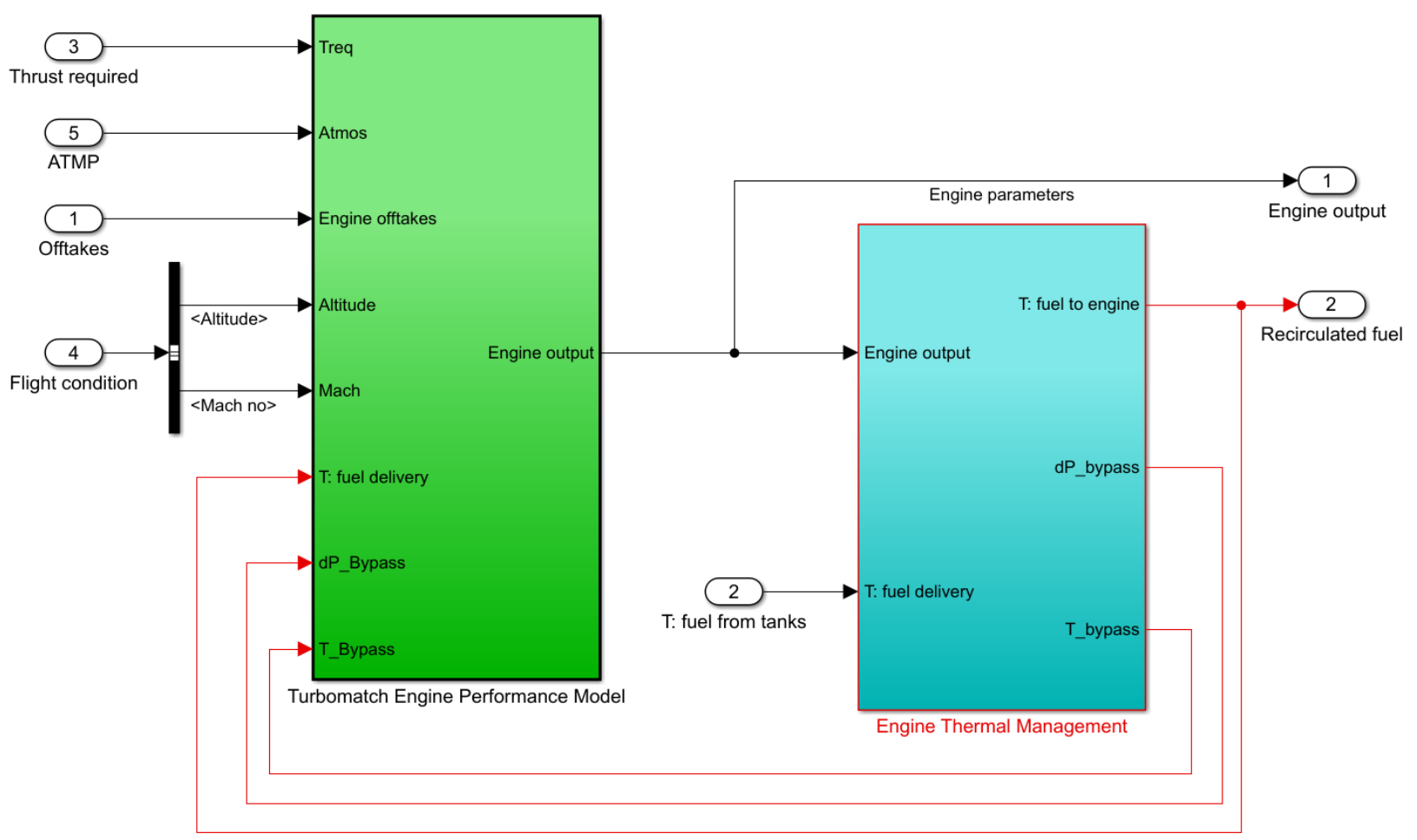

Fig. 2 Simulink diagram of the Engine block.

\section{B. Mission, Atmosphere, and Aircraft Performance}

Inside the Mission Control block, at each time step, the altitude and cruise distance flown are fed into a selected 'Mission profile' block (as determined by the mission switch). This information is used by the selected profile block to determine in which mission segment (climb, cruise, descent, etc.) the aircraft is currently in and when to switch to the next segment. The output of the block are the mission segment parameters required by the other simulation blocks. These include Mach number, climb/descent rate, and so forth, as well as a unique segment id number - a number that is used by the other blocks to determine which segment-specific processes should be executed. The mission segment blocks are stored in a library and the user can easily assemble a variety of different mission profiles by arranging/adding/removing the blocks and by changing the governing mission parameters as desired. A simpler mission profile option, in which the user can simply complete a table with altitudes and Mach numbers describing a flight profile, is also available.

The 'Atmosphere Model' uses the altitude value at each time step to determine the current atmospheric pressure, temperature, density, viscosity, and speed of sound. The model is based on the Military Handbook MIL-HNDB-310 [32] and enables the user to select either a standard (STD), hot (HOT), or cold (CLD) day.

The aircraft performance block solves a 2-D lift and drag force balance for the selected mission profile and user-defined aircraft mass and drag polar data sets. These three main inputs describe the top-level characteristics of the aircraft under study. The outputs encompass a number of aircraft performance variables which are fed to the other blocks. These include flight states (altitude, flight velocities, and Mach number, as well as the total and cruise distance flown), aircraft gross mass (updated by using the mass flow rate of fuel burned by the engine and the simulation time step), and thrust required of the engines.

\section{Engine}

The engine model includes an engine performance model and an engine thermal management model (Fig. 2). The performance model was created using Cranfield University's Turbomatch gas turbine modeling software [33]. Any appropriate engine could be inserted here, and it is endeavored to simulate more types of engines in the near future.

The performance model takes as input the current altitude and Mach number; thrust required (as calculated by the aircraft performance block), the temperature of the fuel delivered (which comes from the engine thermal management 
Table 3 Engine performance output parameters.

\begin{tabular}{ll}
\hline \hline Parameter & Purpose \\
\hline Thrust specific fuel consumption (TSFC) & $\begin{array}{l}\text { To be used, along with the mass of accumulated fuel burned over a } \\
\text { mission, as a key performance indicator to evaluate different thermal } \\
\text { management architectures. } \\
\text { Used in the aircraft performance block to update the fuel and aircraft } \\
\text { gross mass. }\end{array}$ \\
Fuel mass flow rate & $\begin{array}{l}\text { Used in the engine thermal model to calculate heat losses. } \\
\text { Used in the engine thermal model to calculate heat losses. }\end{array}$ \\
$\begin{array}{l}\text { Low-pressure shaft rotational speed } \\
\text { Power extracted by power gearbox }\end{array}$ & $\begin{array}{l}\text { Used in the engine thermal model to calculate heat losses. } \\
\text { Power extracted by accessory gearbox } \\
\text { Bypass duct air pressure }\end{array}$ \\
Bypass duct air temperature & $\begin{array}{l}\text { Used in the engine thermal model for pressure of the cold-side fluid of } \\
\text { bypass duct heat exchangers. } \\
\text { Used in the engine thermal model for temperature of the cold-side } \\
\text { fluid of bypass duct heat exchangers. }\end{array}$ \\
\hline \hline
\end{tabular}

system), the required mechanical, electrical, and bleed offtakes (calculated by the airframe systems block - see Section IV.D; and the atmospheric temperature, pressure, and density, as calculated by the atmospheric block. Another important input is 'dP_Bypass', which feeds data accounting for possible pressure drops in the air in the bypass duct. Such pressure drops could arise because of thermal management equipment, such as heat exchangers, which use the air as a cooling fluid. These pressure drops essentially produce cooling drag. Likewise, there is also an input accounting for the increase in temperature in the bypass duct (T_Bypass) originating from, for example, heated air exiting a heat exchanger. Several outputs are produced, as listed in Table 3

The combined engine thermal management system (Engine TMS) and airframe thermal management blocks (presented in the next subsection) are intended to house novel thermal management architectures for investigation. The purpose of the engine thermal management block is to compute the heat loads produced by the engine components and simulate the transport of this heat to the aircraft heat sinks. It therefore interfaces with both the engine and airframe.

The engine TMS implementation currently in the tool (Figure 3) is an example based on the engine thermal management architecture presented in [34]. In this implementation, heat from the power gearbox, the generators, accessory gearbox, and the bearings is rejected to the engine oil, which, in turn, rejects the heat to the bypass duct air and fuel feed, by means of air-oil and fuel-oil heat exchangers (AOHE and FOHE), respectively. Some of the heated fuel can be recirculated back to the fuel tank, as shown in Fig. 2 The Airbus A320 family makes use of such a fuel recirculation system [16]. As part of the TMS modeling, several physics-based and empirical thermal models were developed to account for different heat loss mechanisms in the engine. For the gearboxes, these included models for load-dependent heat losses (bearing friction and gear mesh losses) and load-independent losses, such as bearing churning, gear windage, and oil seal losses. For the shaft bearings, heat losses were modeled with semi-empirical methods. The waste heat produced by the engine electrical generators was modeled by summing the losses due to eddy currents, hysteresis, and windage. Thermal loads generated by accessory components, such as the pumps and constant speed drives, were calculated using their input power and mechanical efficiencies.

\section{Airframe}

As with the Engine block, the Airframe block constitutes separate performance and thermal behavior blocks (see Fig. (4). A different subsection is devoted to each below.

\section{Systems Performance}

This block contains empirical and physics-based models for the environmental control system (ECS), ice protection system (IPS), hydraulic power system (HPS), electrical power system (EPS), and flight control system (FCS). For each of these, there is the option to switch between a conventional and more-electric architecture.

The block takes as input atmospheric data, flight condition parameters (altitude and Mach number), the flight phase in which the aircraft is currently in (i.e. take-off, cruise, etc.), as well as detailed aircraft-related information, such as geometry, materials, payload, and so forth. The outputs are the bleed air and mechanical and electrical power offtakes required from the engine. 


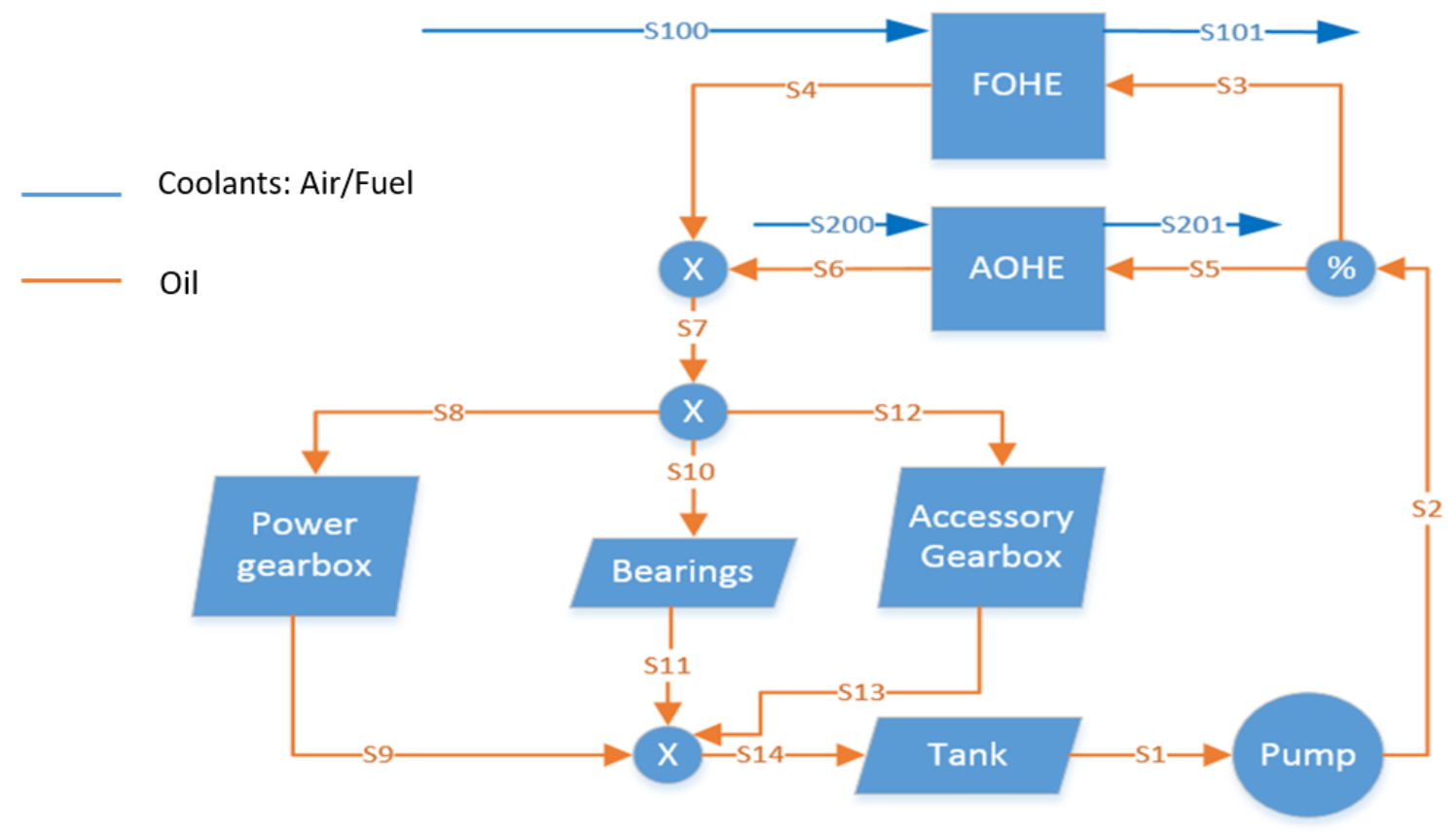

Fig. 3 Schematic of the baseline engine thermal management system employed in the framework (based on Ref. [34]). FOHE - Fuel-oil heat exchanger; AOHE - Air-oil heat exchanger.

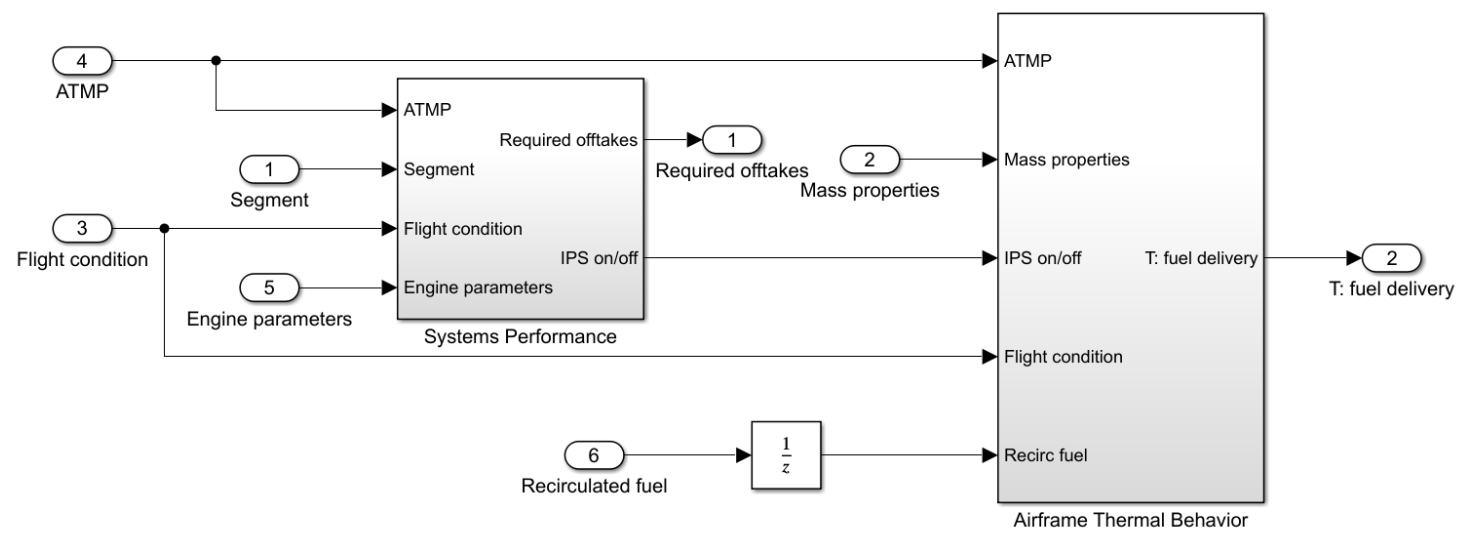

Fig. 4 Simulink diagram of the airframe block. 


\section{Airframe (wing) thermal model}

In this block, the thermal behavior of the airframe is simulated, along with any active temperature control systems that may be required. This block is the second block (along with the Engine TMS block) that is dedicated to house new thermal management architectures. At the current state of development, it only contains a wing thermal model (the focus of the current paper). An earlier version of this model was discussed in previous work by the authors (see Ref. [35]) but is elaborated upon here.

At each time step, the block takes as input the current mass of fuel left in the tanks, atmospheric conditions, Mach number and true airspeed, mass flow rate and temperature of recirculated fuel, and the heat loads from systems in close proximity to the fuel tanks, including actuators, hydraulic lines, bleed air, air conditioning packs, and so forth. The output includes the bulk fuel and ullage temperatures, along with the temperatures at the tank walls. The bulk fuel temperature from the appropriate tank (selected based on the aircraft fuel burn sequence), is provided as input to the engine thermal management system.

The wing thermal model consists of an assembly of 'thermal compartments.' A thermal compartment is defined here as a volume enclosed by solid walls. It could have multiple internal fluids, for example, fuel, ullage, and air. Fluid can enter and exit the compartment at user-specified mass flow rates. The compartments are treated as control volumes to determine the heat transfer into and out of them, while accounting for any possible heat generated inside. Each of the walls surrounding a compartment has an interior and exterior temperature node, whereas the internal fluids each have a single bulk temperature node.

To create the complete wing thermal model, a computational procedure was established to assemble multiple thermal compartments to create a network of temperature nodes. The output of this procedure (the geometry and node input to the simulation) is simply a set of vectors that contains the areas, thicknesses, and material types of the walls, the bulk velocities and properties of the internal fluids, and initial conditions for the temperature nodes (specified by the user, e.g. refuel temperature for fuel, or current prevailing atmospheric temperature). Another output vector contains information about how the compartments relate to each other in three-dimensional space, as, for example, the internal wall of one compartment could be the external wall of another. There is also a 'boundary condition vector,' which dictates the boundary condition temperatures of the external walls of the outer compartments of the wing model. These are either set to a specified temperature, or to the ram or recovery air temperatures.

Waste heat produced by internal system components, such as pipes, pumps, heat exchangers, or assemblies, such as actuators and the air-conditioning packs can also be accounted for using this approach. This can be done by providing the waste heat values in another vector, or by specifying the surface temperatures on the components, in which case some geometrical and heat transfer mechanism information has to be provided, from which the rate of heat transfer from the component can subsequently be calculated.

An example thermal network for the wing of an Airbus A320 is presented in Fig. 5, which shows a simplified sectioned side view of the wing, as well as the top view of the wing and center fuselage. As can be seen, the slats, fixed leading-edge, fuel tanks, fixed trailing-edge, and flaps are all treated as thermal compartments. This does not necessarily have to be the case and the thermal model could, for example, be reduced to only the fuel tank, in which case the exterior nodes of the tank walls will be the boundary condition nodes.

This thermal compartment assembly approach is highly flexible, as it enables the user to swiftly and easily set up thermal models for many different aircraft. Not only can it be used to model fuel tanks, but also surrounding volumes, such as the ECS and hydraulic compartments, wheel bays, and the leading and trailing edges, which contain actuators, bleed ducts, and so forth. In addition, the use of the vectors containing the geometry and heat transfer information does away with the need to change any code performing the actual thermal simulation across different aircraft.

To perform the thermal simulation, the one-dimensional heat transfer calculation procedure described in [36] is followed, where the heat flow at each node is equated with the change in its total heat capacity (i.e. a heat balance is applied to solve the node network). Applying this for all the unknown node temperatures leads to a set of temperature-time differential equations, which can be solved numerically.

The convection heat transfer coefficients are calculated at every time step for heat transfer between the fluids and structural nodes. Between a structural wall, $i$, and the fluid in contact with it, the heat transfer rate can be calculated as follows:

$$
\dot{Q}_{\text {conv }, i}=h A_{i} \Delta T
$$

In this equation, $\Delta T=T_{i}-T_{b}$ is the temperature difference between the surface node of the structural wall $i$ and the bulk node of the fluid in contact with it. $A_{i}$ is the surface area of the wall, and $h$ is the convection heat transfer 


\section{Sectioned side view}

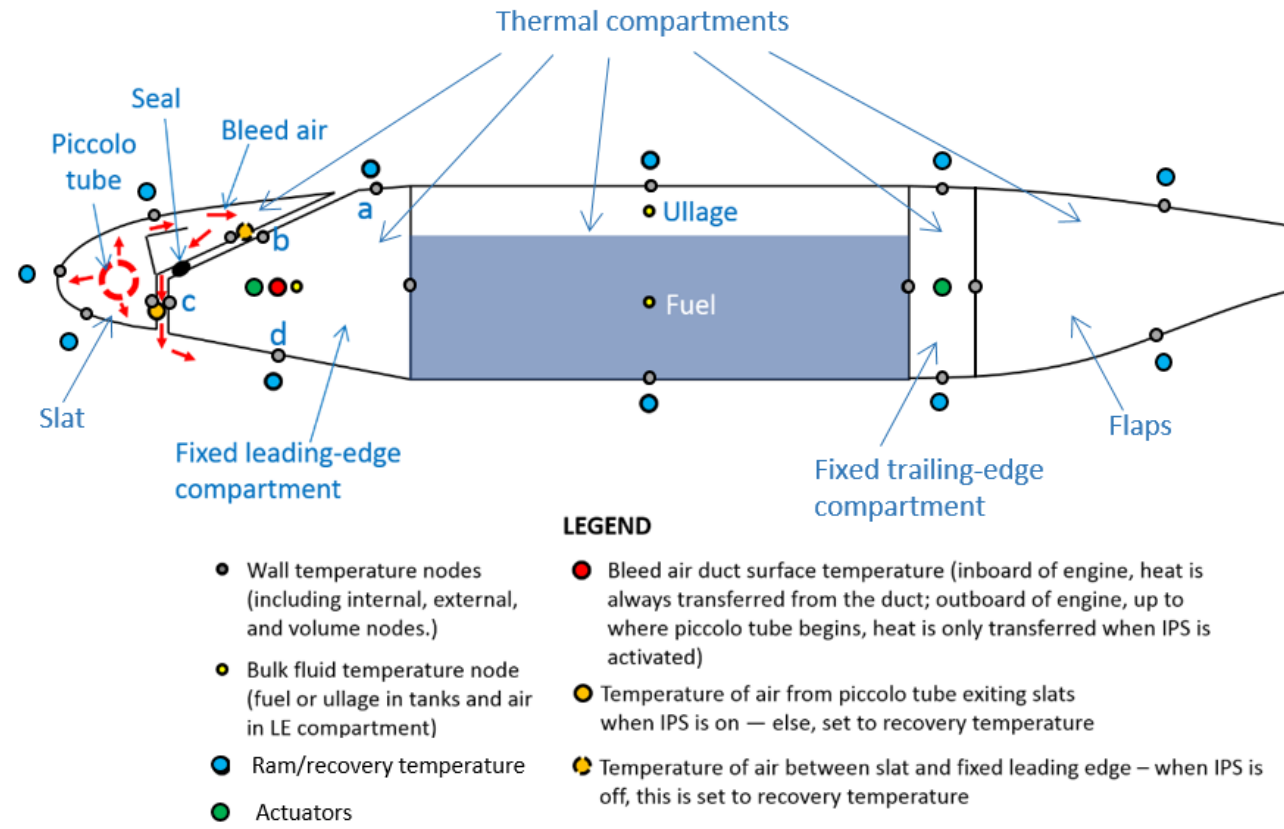

\section{Top view}

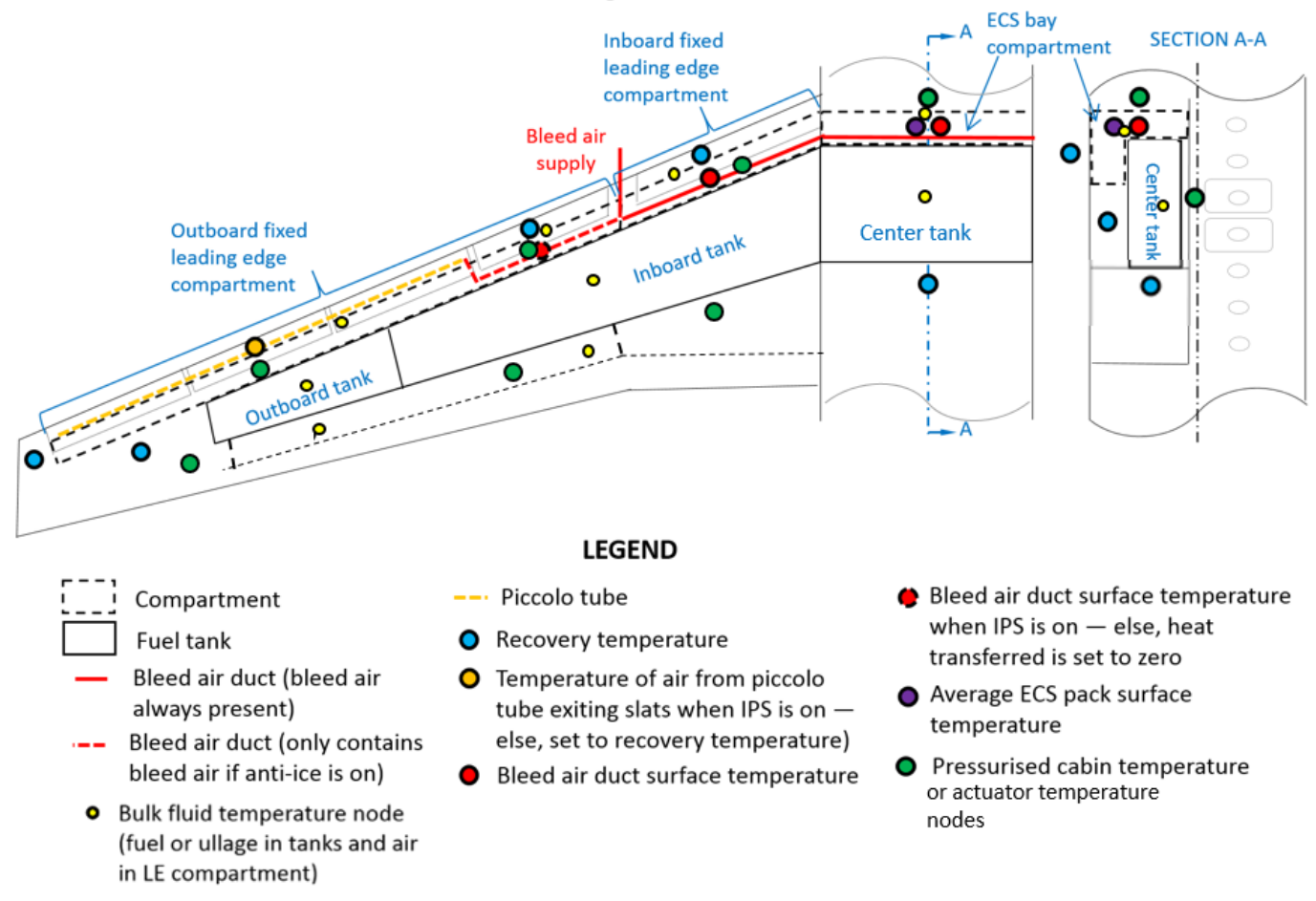

Fig. 5 Wing thermal node network. This example is based on the A320 wing and fuel tank arrangement, with simplified geometry. Adapted from Ref. [35]. 
coefficient, which is calculated with the methods presented in Çengel [37]. The convention is that $Q_{c o n v, i}$ is positive if the heat flows from the wall to the fluid.

Conduction through wall $i$ is calculated as follows:

$$
\dot{Q}_{\text {cond }, i}=\frac{k A_{i}}{d_{i}} \Delta T
$$

Here, $\Delta T=T_{i n t}-T_{\text {ext }}$ is the difference in temperature between the interior and exterior nodes of the wall, $k$ is the wall material thermal conductivity, and $d_{i}$ is the wall thickness. $\dot{Q}_{c o n d, i}$ is positive if the heat is transferred from the interior to the exterior of the wall.

Employing the Euler method, the temperature of the bulk fluid is updated as follows:

$$
T_{b, n}-T_{b, n-1}=\frac{\dot{Q}_{f l}+\sum \dot{Q}_{c o n v, i}+\sum \dot{Q}_{g e n}}{c_{p, b} \rho_{b} V_{b}} \Delta t_{s i m}
$$

$T_{b, n}$ and $T_{b, n-1}$ are the temperatures at the current and previous time steps; $\dot{Q}_{f l}$ is the heat transfer rate between the fluid and another fluid which may be in contact with it (e.g. fuel in contact with ullage). The sum in the second term of the numerator represents the convection heat transfer at all the thermal compartment boundaries which border the fluid. The second sum accounts for the addition of all heat generating sources inside the fluid. The variables $c_{p, b}, \rho_{b}$, and $V_{b}$ are the bulk fluid specific heat, density, and volume, respectively. The simulation time step duration is user-defined and represented by $\Delta t_{\text {sim }}$. Similarly, the temperature of the surface nodes of wall $i$ is updated as follows:

$$
T_{i, n}-T_{i, n-1}=2 \Delta t_{s i m} \frac{-\sum \dot{Q}_{c o n v, i}+\dot{Q}_{c o n d, i}}{c_{p, i} \rho_{i} V_{i}}
$$

Here, $\dot{Q}_{c o n v, i}$ are the convection heat transfer rates between the wall and the different fluids in contact with it. $C_{p, i}$, $\rho_{i}$, and $V_{i}$ are the material specific heat, material density, and volume occupied by the wall, respectively. Note that the sign in front of $\dot{Q}_{c o n d, i}$ depends on whether the node is for the internal or external surface.

For the fuel tanks, the fuel levels are updated by subtracting the mass of fuel burned during the time step. The temperature of the engine fuel feed is then set equal to the bulk temperature of the fuel in the currently used tank. The current tank selected is based on the fuel burn sequence of the given aircraft.

\section{Wing thermal model validation}

The wing thermal model was validated by comparing the results it produced with publicly available data. The aircraft selected for this purpose was the Airbus A310, for which data for fuel temperatures were found in Ref. [38]. The A310 was duly modeled and implemented in the Simulink tool embodying the framework. Initial results showed that the model produced similar trends to that of the published data, but that heat transfer took place at a lower rate during the initial climb and late descent and for the outer tank in general. This was attributed to assumptions regarding the fuel velocity in the tanks - a difficult parameter to establish, as little relevant data is publicly available. The model therefore had to be calibrated by manually increasing the heat transfer coefficients calculated, by multiplying them with 'calibration' factors. Only the outer tank was calibrated and its calibration factor was set to 1.5. This produced the results shown in Fig. 6 As can be seen, the temperature error is less that $2.5 \mathrm{~K}$ across the whole flight, except at the beginning and final minutes of the flight. The reason for the discrepancy could be significant sloshing in the tanks during these phases of the flight, which would promote heat transfer more than what was modeled for. However, given the relatively simple thermal models, these results show reasonable agreement with the published data and, for the purpose of performing ordinal comparative studies, it was deemed that the wing thermal model sufficed.

\section{Case study: single-aisle transport with geared UHBR turbofan engines}

To demonstrate some of the capabilities of the framework, a short case study is presented in this section. This study involved using the framework to simulate the thermal behavior of a single-aisle medium-range aircraft with GTF UHBR engines. The goal was to determine the temperature of the fuel and ullage in the fuel tanks across a complete flight in different atmospheric conditions (standard, hot and cold days) and for different airframe materials (metallic vs. composite). Another goal was to present results for some of the main parameters that would be needed as input for thermal management system design for GTF UHBR engines. These are the power consumed by the power and accessory gearboxes and the heat sink temperatures in the engine, namely those of the bypass duct air and fuel feed temperature. 

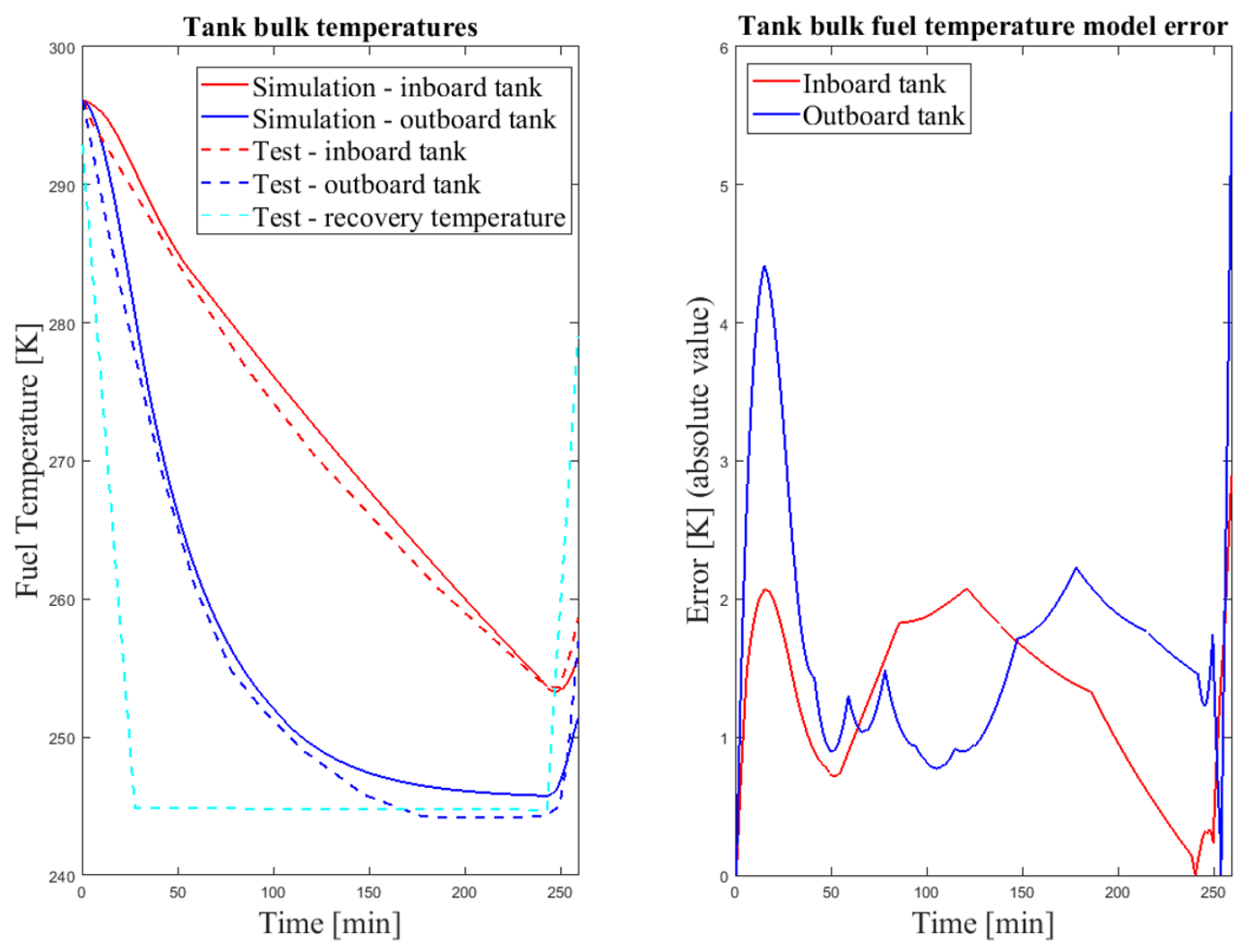

Fig. 6 Validation of wing thermal model fuel tank temperatures (test data is from Airbus [38]).

\section{A. Simulation setup}

An airframe model was created that closely reflects the geometric and aerodynamic properties of the Airbus A320. The engine model devised in the Turbomatch software is representative of a high bypass ratio (15:1) turbofan with $25,000 \mathrm{lb}$ of thrust and incorporates a power gearbox to lower the fan rotational speed. The mission block in the Simulink tool was set up to create a mission profile representative of the design mission of the Airbus A320. The main mission parameters are provided in Table 4 Time is also spent before the beginning and after the end of the flight where the aircraft is on the ground. The initial values for the fuel and ullage temperatures were set equal to a 'refuel' value of $22.95{ }^{\circ} \mathrm{C}$. All other nodes were set to the prevailing ground ambient air temperature.

\section{B. Results}

The flight conditions and aircraft performance results are shown in Figure 7. Note that, because the cruise distance and Mach number are the same but the speed of sound differs for the standard, hot, and cold days, the flights on each of these days have a different duration.

\section{Fuel and ullage temperature histories for different atmospheric conditions}

The mass of fuel available in the tanks are shown in Figure 8 . The center tank is almost empty at the start of the flight, and the fuel feed switches to the inboard tanks just before 30 minutes into the flight. Fuel from the outboard tanks is not used. The differences in fuel burn rate across the standard, hot and cold days are attributed to the differences in 

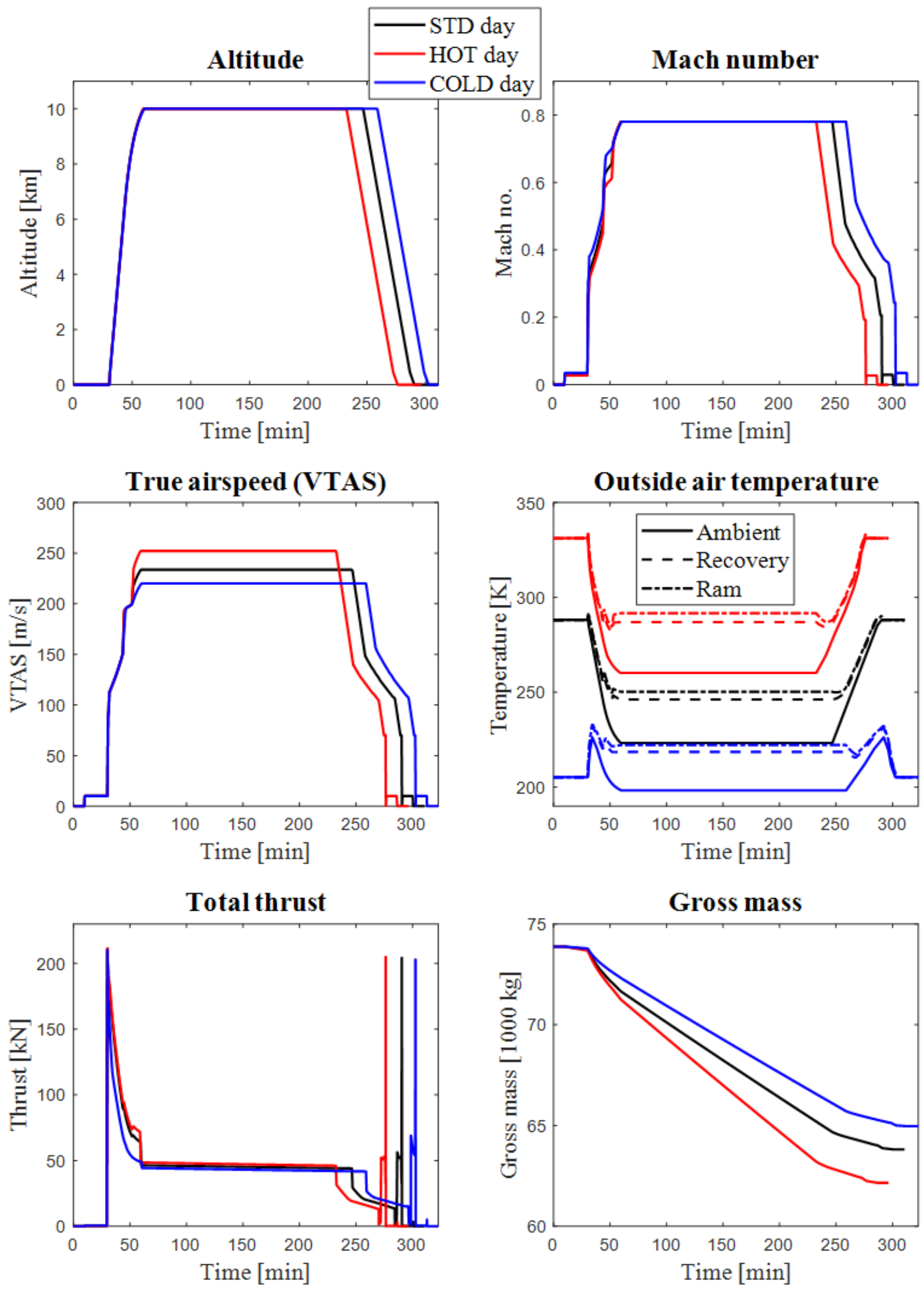

Fig. 7 Flight conditions and aircraft performance during simulated mission. 


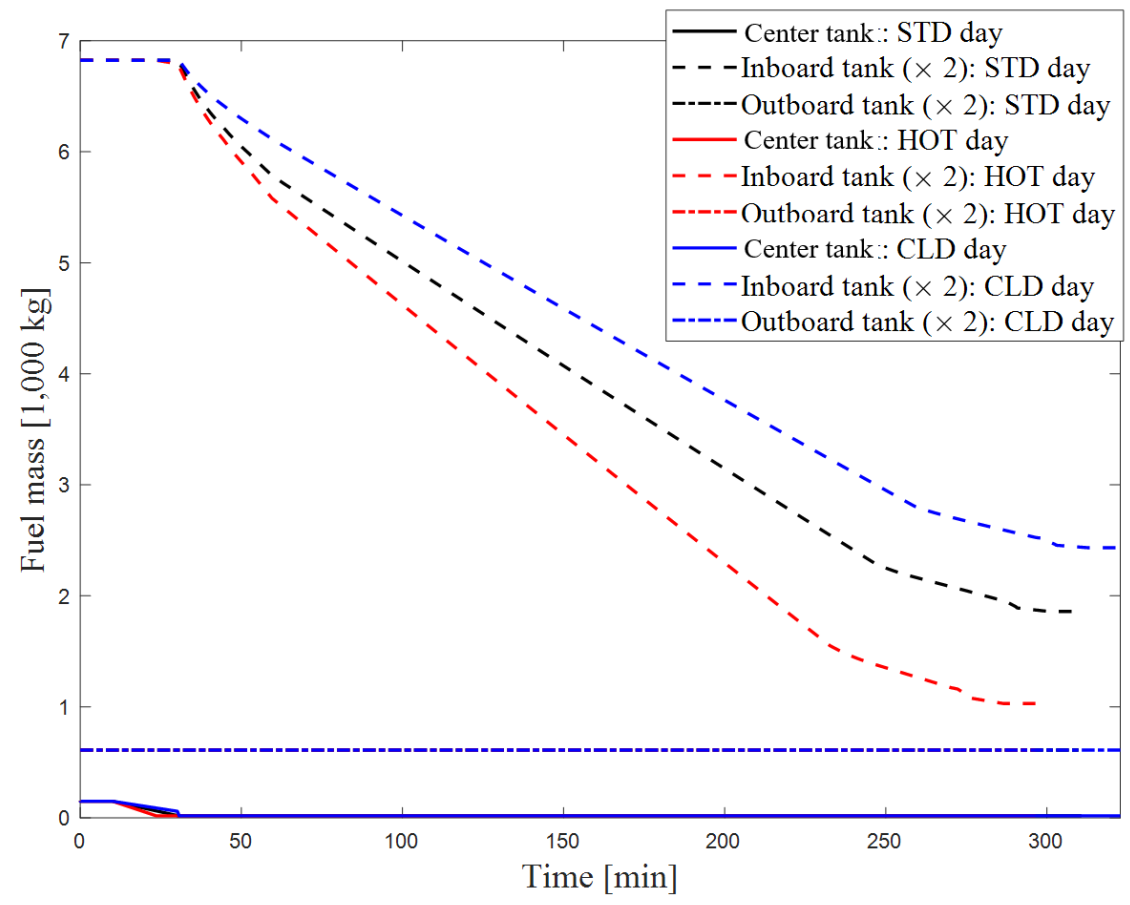

Fig. 8 Fuel available in tanks. Note: there are two inboard and two outboard tanks (because of the symmetry of the wings) and the values shown should therefore be multiplied by two to obtain the total onboard fuel available from these tanks.

engine efficiency across these different conditions.

Fuel and ullage temperatures across the flight on standard, hot and cold days are shown in Fig. 9. As can be seen, on the standard day, the fuel temperature in all the tanks remains well above the freezing points of both Jet A and Jet A1 fuel. However, the fuel in the center tank is in the flammable temperature range for a substantial amount of time (from climb to about halfway into the cruise). This is why center tanks are often inerted. As expected, the temperatures all approach the recovery temperature of the atmospheric air.

On the 'hot' day, the center tank is actually above the upper flammability limit for most of the flight, while the inboard and outboard tanks are flammable throughout almost the whole flight. This is an extreme atmospheric case (occurring only about $1 \%$ of the time), but a full flammability exposure analysis would have to be conducted and flammability reduction means may be needed. On the cold day, the tanks are safely outside the flammability limits, but the inboard and outboard fuel temperatures drop well below the freezing points of jet fuels. This would be an unacceptable condition and fuel heating would be required. One way in which this can be performed is by recirculating hot fuel from the engine cooling system back into the tanks.

\section{Fuel temperatures for different airframe materials}

Fig. 10 shows the results for fuel temperatures when the airframe is constructed from Aluminum alloys compared with composite carbon-fiber reinforced polymer (CFRP) materials. As can be observed, the fuel temperature decreases faster with Aluminum alloys, because of the higher thermal conductivity. However, this is not true for the enclosed center tank, because convection with the atmosphere and subsequent conduction through the tank walls do not dominate as they do in the inboard and outboard tanks. Rather, the effect that does dominate relates to the lower specific heat of CFRP, combined with the low mass (and hence lower thermal inertia) of the fuel in the center tank. Because of the lower specific heat, the temperatures of the CFRP walls drop faster than with Aluminum and, because of the lower thermal inertia of the fuel in the center tank, the fuel loses heat faster and its temperature approaches that of the tank wall temperatures. Note that the use of CFRP renders the inboard tank flammable for slightly longer than when Aluminum alloys are used. 

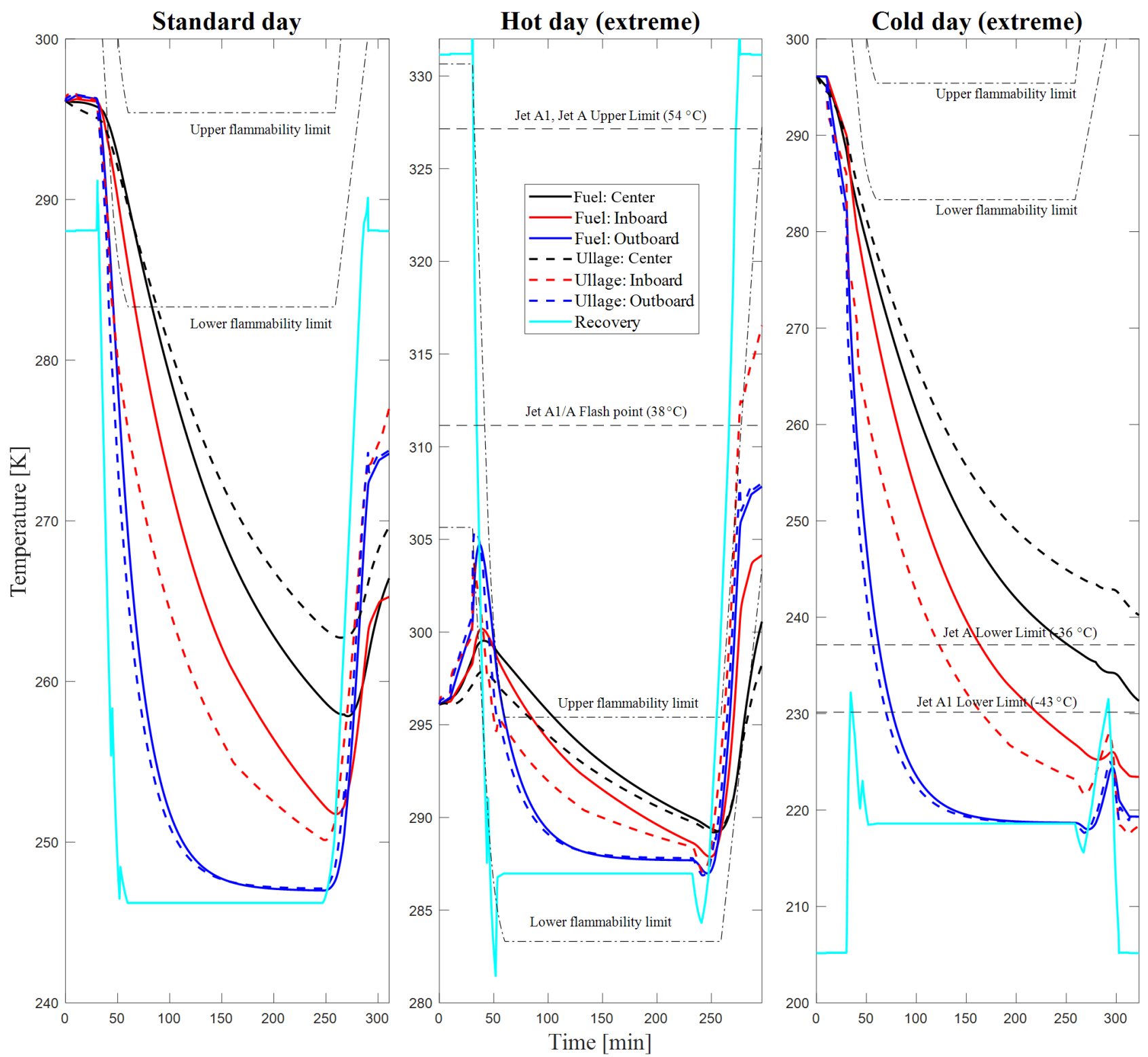

Fig. 9 Bulk fluid temperatures in the fuel tanks. 


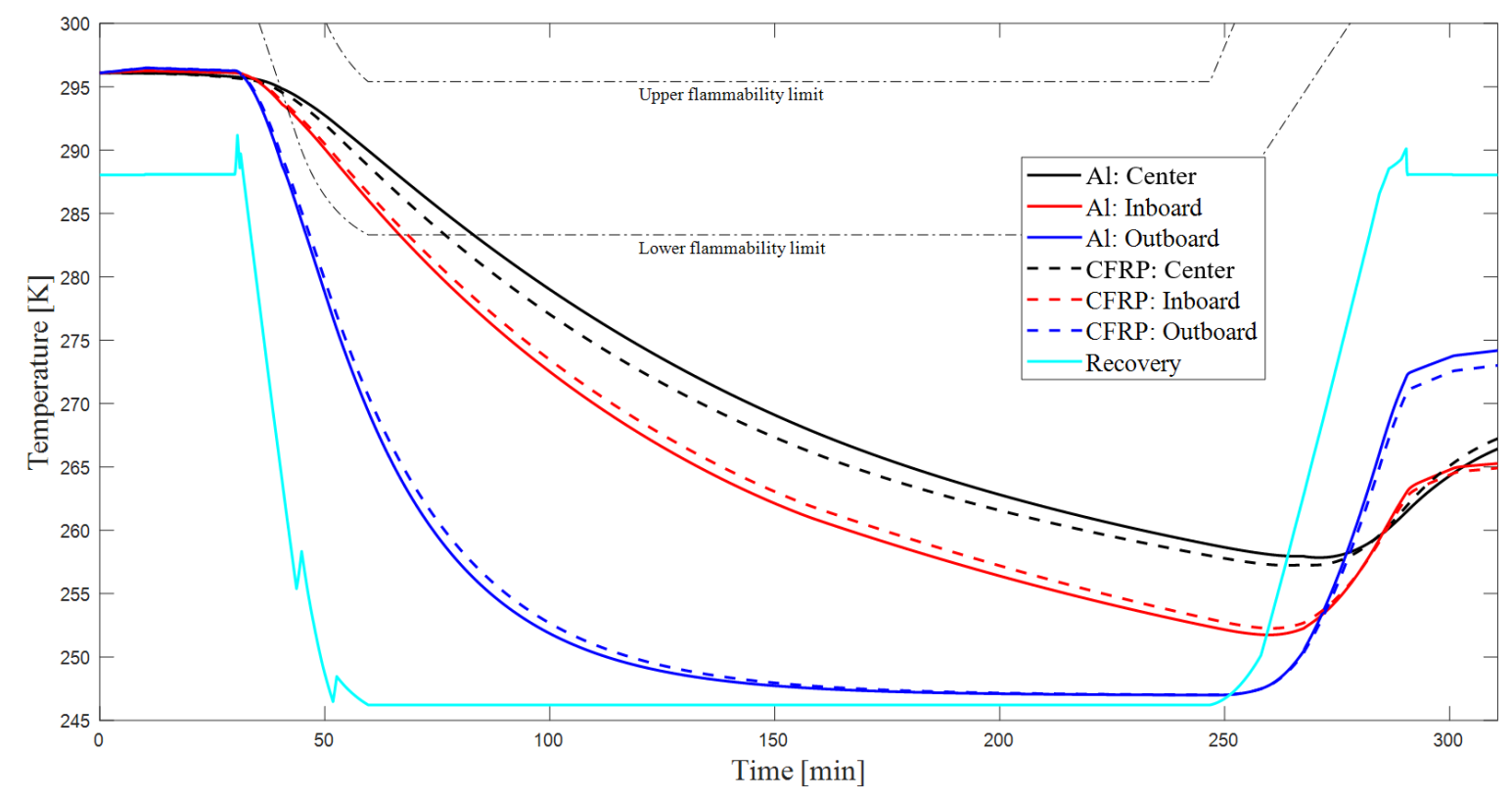

Fig. 10 Bulk fuel temperature comparison for Aluminum alloy and CFRP airframe materials (standard day).

\section{Engine heat sink temperatures}

The results for the heat sink temperatures in the engine are presented in Fig. 11. The 'kinks' in the fuel temperatures are caused by the switch from the center tank to the inboard tank, which takes place when the former empties. As can be seen, there is a large variation in the sink temperatures across different atmospheric conditions. The higher temperatures associated with the hot conditions means that less cooling would be available, unless the mass flow rates could be increased. For bypass air, this would entail higher drag because of the increased momentum loss of the air in the bypass duct. For the fuel, if the mass flow rate would exceed that required by the engine, it will have to be recirculated back to the fuel tanks, which would increase the temperature of the fuel even further. For more electric aircraft and aircraft with UHBR engines, this might present serious problems, as the waste heat produced could exceed that which can be efficiently, or even safely, be removed. This underpins the need for novel, innovative thermal management systems.

\section{Engine gearbox input power}

Figure 12 shows the power taken by the accessory gearbox (which results from power required by airframe systems), as well as that of the power gearbox (which drives the fan). As can be seen, the power input to the power gearbox is exceedingly large and, even with highly efficient gearboxes, the waste heat generated will be considerable.

\section{Effects of thermal systems on fuel consumption}

A final study is presented here to demonstrate the capability of the framework to cater for studies of the effects of thermal management system (TMS) components on the aircraft fuel consumption. The results from this study are shown in Figure 13 Three cases are shown: the data shown in black is for a hypothetical case in which there is no fuel-oil or air-oil heat exchangers (FOHEs or AOHEs), and it is assumed that heat from the engine is removed by some other means. The data in red is for the full TMS introduced in Section IV.C, i.e. with the effects of the FOHE on the fuel temperature and pressure drop and temperature rise in the bypass duct caused by the AOHE accounted for. The blue data represents another hypothetical case, in which the AOHE is eliminated and it is assumed that the heat that was supposed to be removed by it is removed in some other manner with negligible effect on fuel burn. As can be seen, using the FOHE markedly improves fuel consumption. This is because, as the fuel passes through the fuel-oil heat exchanger (FOHE), its temperature rises, which increases its caloric value and it subsequently combusts more efficiently. It can also be seen that the configuration without the air-oil heat exchanger (AOHE) is more efficient, as the momentum drag the AOHE causes is eliminated. To realize this configuration, an alternative technique would need to be found that 


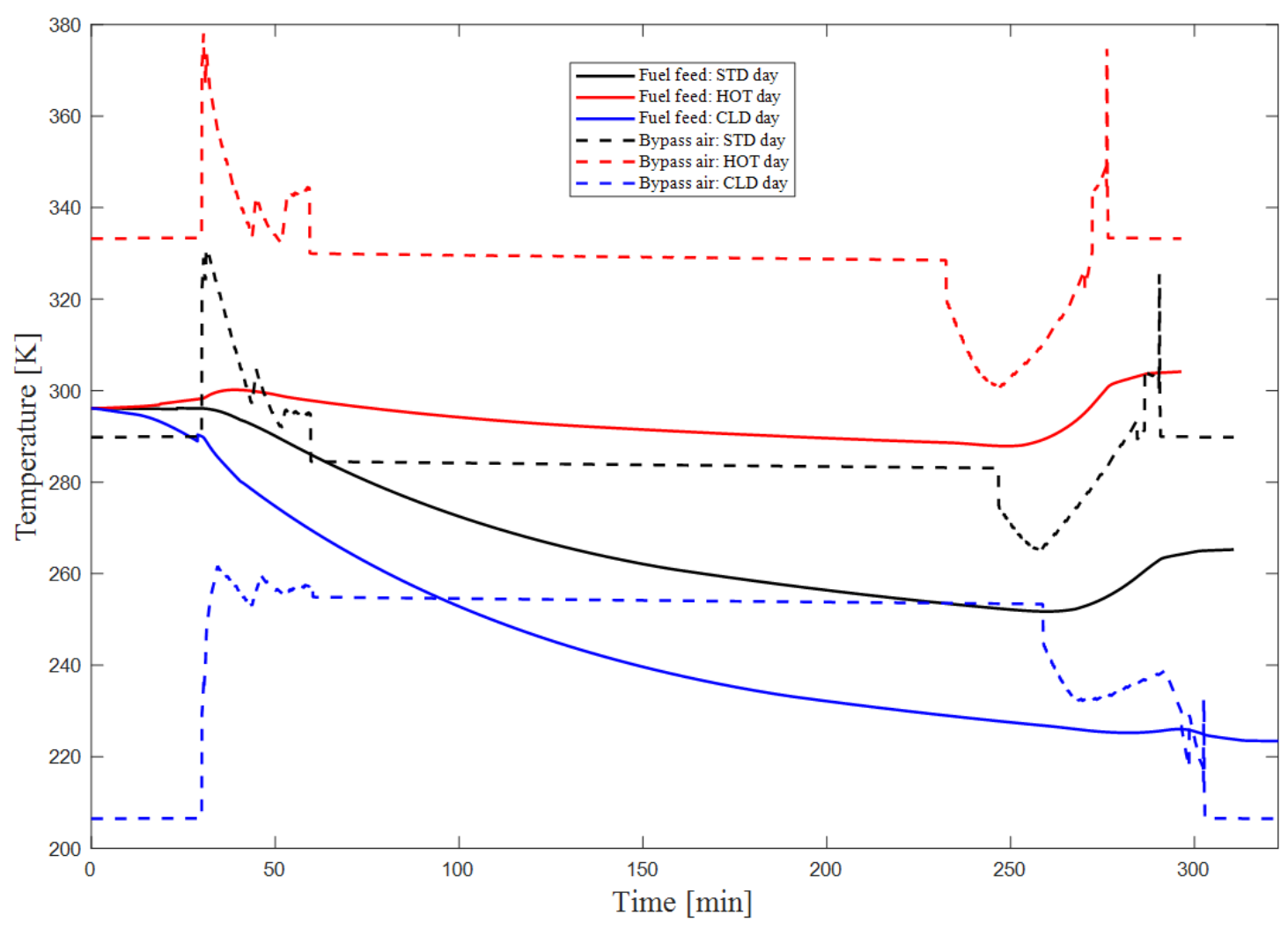

Fig. 11 Engine heat sink temperatures.

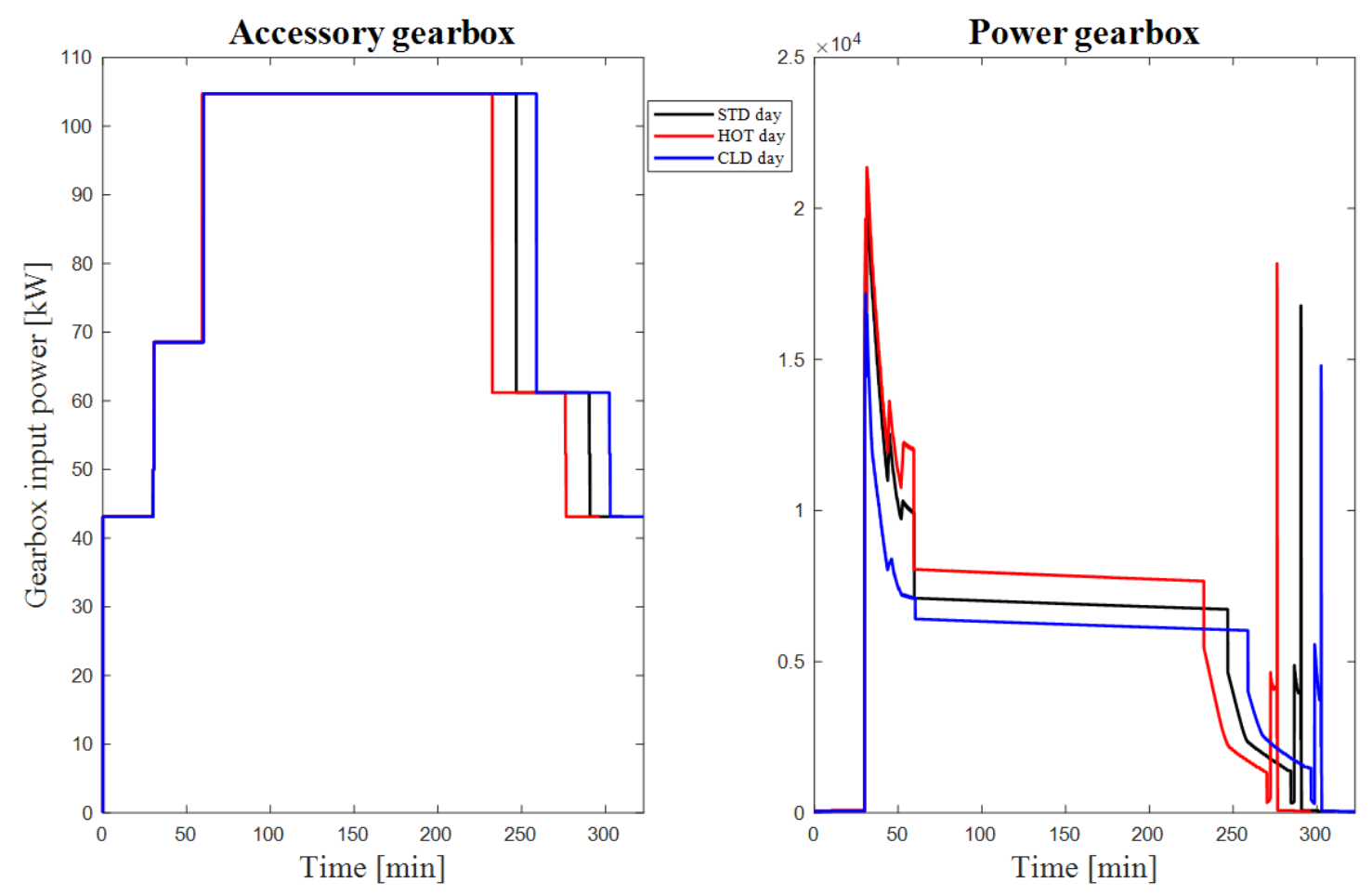

Fig. 12 Engine gearbox input power. 

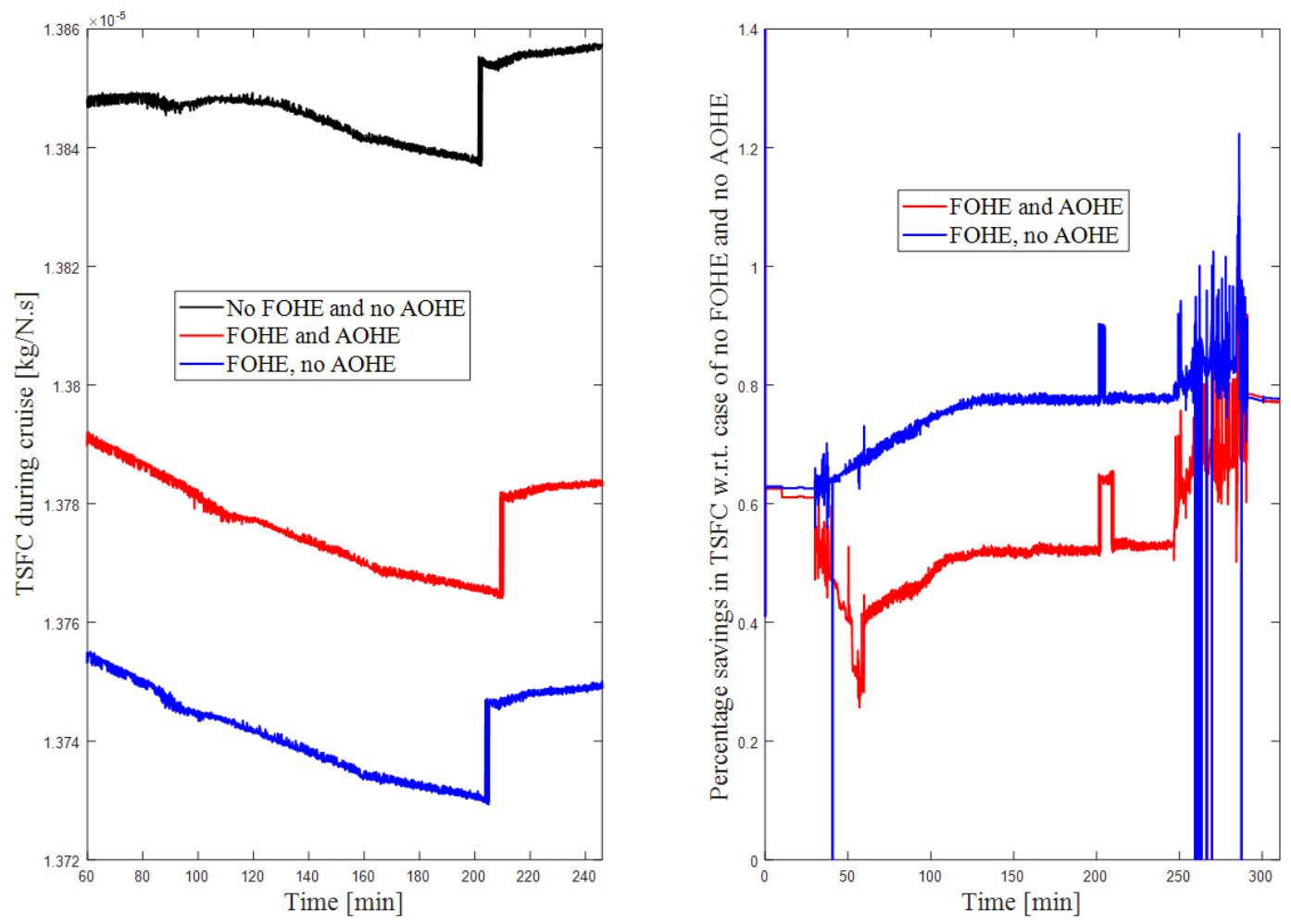

Fig. 13 Percentage savings in TSFC for different TMS configurations (STD day).

would allow the AOHE to be eliminated without inducing other performance penalties. The percentage savings, with respect to the no-FOHE/no-AOHE case, of the full FOHE and AOHE configuration and FOHE-only cases are shown in the right-hand plot of Figure 13 It can be seen that the differences in TSFC in these results are small, but not negligible, and can amount to a substantial amount of savings in fuel burn over time.

\section{Conclusion}

In this paper, a framework for integrated dynamic thermal simulation of future civil transport aircraft was presented. This framework enables coupled airframe-engine thermal and performance analyses to be performed and was specifically developed to model and simulate novel thermal management solutions for future civil aircraft. The integrated nature enables analyzing the impact of different thermal architectures on overall aircraft performance, by appropriately combining models for airframe and systems thermal behavior, as well as aircraft and propulsion characteristics.

The focus in this paper was primarily on the wing thermal model and the results that it provides for the thermal behavior of fuel when considering different factors. This is because of the importance of fuel as a heat sink and the significance of its thermal behavior when considering safety. A simple wing-thermal modeling approach was introduced, which involves a procedure for assembling a number of generic 'thermal compartments'. These can be used to model fuel tanks, but also surrounding volumes, such as the ECS and hydraulic compartments, wheel bays, and the fixed leading and trailing edges, which contain actuators, bleed ducts, and so forth. The approach is highly flexible, as it enables the user to easily insert wing thermal models for different aircraft without having to change the thermal simulation code itself. The wing thermal model was validated with published data for the Airbus A310.

The framework was demonstrated by means of a simple case study involving a single-aisle passenger airplane with ultra high high bypass ratio geared turbofan engines. Fuel temperature results were provided for different atmospheric conditions and airframe materials, which showed the substantial variation in temperatures that could be expected and the resulting divergent implications regarding flammability and freezing. Results were also provided for input parameters to the engine thermal management system that will be required. These are the engine heat sink (bypass duct and fuel feed) temperatures and the power input to the accessory and power gearboxes.

Future work will involve further validation of the framework, testing it on more aircraft, and employing it to 
devise novel thermal management architectures. It is also intended to add more capability, especially by introducing performance and thermal models for other future propulsion and airframe concepts.

\section{Acknowledgments}

This work was conducted under the Ultra High Bypass Ratio Aero Engine Thermal Systems (UHBR Thermals) Programme, funded by Meggitt PLC, as lead partner, and Innovate UK (grant No: 91855-263266).

\section{References}

[1] Krein, A., and Williams, G., "Flightpath 2050: Europe's vision for aeronautics," Innovation for Sustainable Aviation in a Global Environment: Proceedings of the Sixth European Aeronautics Days, 2012, p. 63.

[2] Wheeler, P., and Bozhko, S., “The more electric aircraft: Technology and challenges.” IEEE Electrification Magazine, Vol. 2 , No. 4, 2014, pp. 6-12.

[3] Larsson, L., Grönstedt, T., and Kyprianidis, K. G., "Conceptual design and mission analysis for a geared turbofan and an open rotor configuration," ASME 2011 Turbo Expo: Turbine Technical Conference and Exposition, Citeseer, 2011, pp. 359-370.

[4] Verseux, O., and Sommerer, Y., "New challenges for engine nacelle compartments pressure and thermal loads management with aircraft engine evolution," 29th Congress of the International Council of the Aeronautical Sciences, ICAS $2014,2014$.

[5] Karimi, K. J., "Future aircraft power systems-integration challenges (Boeing presentation)," uRL: https://user . eng. umd edu/ austin/ense622.d/lecture-resources/Boeing787-MoreElectricAircraft.pdf 2007.

[6] Sheridan, W., McCune, M., and Winter, M., “Geared Turbofan ${ }^{\mathrm{TM}}$ Engine: Driven by Innovation,” , dec 2015. doi:10.1002/9780470686652.eae1018, URL https://doi.org/10.1002/9780470686652 . eae1018

[7] Blanding, D., "Subsystem design and integration for the more electric aircraft," 5th international energy conversion engineering conference and exhibit (IECEC), 2007, p. 4828.

[8] Rosero, J., Ortega, J., Aldabas, E., and Romeral, L., "Moving towards a more electric aircraft," IEEE Aerospace and Electronic Systems Magazine, Vol. 22, No. 3, 2007, pp. 3-9.

[9] FAA, "Fuel tank flammability reduction means - Advisory Circular 25.981-2A," Federal Aviation Regulations, US Federal Aviation Administration, Washington, DC, USA, 2008.

[10] Aerospace Technology Institute, "UHBR Thermals project,", 2017. URL https://www.ati.org.uk/2017/11/atifundingenables-\{\%\}0Ameggitt-research-thermal-systems-technology/

[11] Ahlers, M. F., Aircraft Thermal Management, Wiley Online Library, 2010. doi:10.1002/9780470686652.eae046, URL https://onlinelibrary.wiley.com/doi/abs/10.1002/9780470686652.eae046

[12] Brines, G. L., and Gray, D. E., "Heat Management in Advanced Aircraft Gas Turbine Engines," ASME 1986 International Gas Turbine Conference and Exhibit, American Society of Mechanical Engineers, Düsseldorf, Germany, 1986, pp. V005T15A003V005T15A003.

[13] Ljubas, D., Krpan, H., and Matanović, I., "Influence of engine oils dilution by fuels on their viscosity, flash point and fire point," Nafta: exploration, production, processing, petrochemistry, Vol. 61, No. 2, 2010, pp. 73-79.

[14] van den Bossche, D., "The A380 flight control electrohydrostatic actuators, achievements and lessons learnt," 25th International Congress of the Aeronautical Sciences, 2006, pp. 1-8.

[15] Streifinger, H., "Fuel/oil system thermal management in aircraft turbine engines," RTO Meeting proceedings, 1999 , pp. 12-1.

[16] Airbus, “A318/A319/A320/A321 Technical Training Manual,” Tech. rep., 2008.

[17] EASA, Certification Specifications and Acceptable Means of Compliance for Large Aeroplanes, Amendment 20, European Aviation Safety Agency, Effective 24 August 2017, 2017.

[18] Kornstaedt, L., "Low fuel temperatures," Airbus FAST Magazine, 2005, pp. 5-11.

[19] Guan, T., "Fuel System Water/Ice Management Using OBIGGS,” MSc thesis, Cranfield University, 2014. 
[20] Terada, Y., "Fuel System Water/Ice Management Using OBIGGS,” MSc thesis, Cranfield University, 2016.

[21] Kang, Z., LIU, Z., REN, G., and LV, Y., Fuel Tank Modeling and Fuel Temperature Simulation of an Aircraft in Steady-State and Transient-State Methods, 2015. doi:10.13140/RG.2.1.3000.9681.

[22] McCarthy, K., Walters, E., Heltzel, A., Elangovan, R., Roe, G., Vannice, W., Schemm, C., Dalton, J., Iden, S., and Lamm, P., "Dynamic Thermal Management System Modeling of a More Electric Aircraft," Tech. rep., 2008.

[23] Sielemann, M., Lee, C., LeBrun, V.-M., Ahn, C., Colleoni, A., Lee, D., Lee, J., Nguyen, A., Proelss, K., and Yoon, H. M., “Aircraft Fuel System Design Using 1D and 3D Methods: An Enabler for Thermal Management," Tech. rep., 2017.

[24] Qian, S., Nan, C. S., and Yu, Y. S., “Analysis of aircraft integrated thermal management using fuel as heat sink," 2016 IEEE International Conference on Aircraft Utility Systems (AUS), 2016, pp. 774-779. doi:10.1109/AUS.2016.7748157.

[25] Doman, D. B., "Optimal cruise altitude for aircraft thermal management," Journal of Guidance, Control, and Dynamics, Vol. 38, No. 11, 2015, pp. 2084-2095.

[26] Wolff, M., “Aerothermal Design of an Engine / Vehicle Thermal Management System,” Tech. rep., NATO, 2011. doi: 10.14339/RTO-EN-AVT-195.

[27] Blázquez, P., "Fuel temperature estimation and energy balance within an UAV integral wing fuel tank," Heat Transfer XIII: Simulation and Experiments in Heat and Mass Transfer, Vol. 83, 2014, p. 463.

[28] Zilio, C., Longo, G. A., Pernigotto, G., Chiacchio, F., Borrelli, P., and D’Errico, E., "CFD analysis of aircraft fuel tanks thermal behaviour," Journal of Physics: Conference Series, Vol. 923, IOP Publishing, 2017, p. 12027.

[29] Newman, R. W., Dooley, M., and Lui, C., "Efficient propulsion, power, and thermal management integration," 49th AIAA/ASME/SAE/ASEE Joint Propulsion Conference, 2013, p. 3681.

[30] Wolff, M., “Aerothermal Design of an Engine/Vehicle Thermal Management System,” Tech. Rep. RTO-EN-AVT-195, North Atlantic Treaty Organization, 2011.

[31] Roberts, R. A., and Decker, D. D., "Control architecture study focused on energy savings of an aircraft thermal management system,” Journal of Dynamic Systems, Measurement, and Control, Vol. 136, No. 4, 2014, p. 041003.

[32] US Department of Defense, "MIL-HNDB-310: Military Handbook: Global Climatic Data for Developing Military Products.”, 1997.

[33] Cranfield University, “The TURBOMATCH Scheme,” Tech. rep., 1999.

[34] Papa, F., Phillips, T., and Phillips, K., “Gas Turbine Engine Thermal Management System,” Patent: EP 2587024 A2. United Technologies Corporation, 2011.

[35] Van Heerden, A. S. J., Judt, D. M., Lawson, C. P., and Bosak, D., "Effects of More Electric Systems on Fuel Tank Thermal Behaviour," More Electric Aircraft Conference, Toulouse, France, 2019.

[36] Lienhard IV, J. H., and Lienhard V, J. H., A Heat Transfer Textbook, $4^{\text {th }}$ ed., Phlogiston Press, Cambridge, MA, 2018. URL http://ahtt.mit.edu

[37] Çengel, Y. A., Heat and mass transfer, $3^{\text {rd }}$ ed., McGraw-Hill, New York, 2006.

[38] Airbus, "Getting to grips with cold weather operations," Tech. rep., Flight Operations Support - Customer Services Directorate, 1999. 
Framework for integrated dynamic thermal simulation of future civil transport aircraft

van Heerden, Albert S. J.

AIAA

van Heerden ASJ, Judt DM, Lawson CP, Jafari S, Nikolaidis T. (2020) Framework for integrated dynamic thermal simulation of future civil transport aircraft. In: 2020 AIAA SciTech Forum, 6-10 January 2020, Orlando, Florida, USA

https://doi.org/10.2514/6.2020-1942

Downloaded from Cranfield Library Services E-Repository 